Copyright

by

Joonho Lee

2007 
The Dissertation Committee for Joonho Lee Certifies that this is the approved version of the following dissertation:

Is Information Uncertainty Positively or Negatively Associated with Post-Earnings-Announcement Drift?

\section{Committee:}

Robert N. Freeman, Supervisor

Ross G. Jennings

Michael B. Clement

Paul C. Tetlock

Thomas W. Sager 
Is Information Uncertainty Positively or Negatively Associated with Post-Earnings-Announcement Drift?

\author{
by \\ Joonho Lee, B.B.A.; M.B.A.; M.P.A.
}

Dissertation

Presented to the Faculty of the Graduate School of

The University of Texas at Austin

in Partial Fulfillment

of the Requirements

for the Degree of

Doctor of Philosophy

The University of Texas at Austin

May 2007 


\section{Dedication}

To My God, Dad, Mom, Sisters, and Minhee 


\section{Acknowledgements}

I would like to express my most earnest gratitude to my committee members: Robert Freeman (chair), Michael Clement, Ross Jennings, Tom Sager, and Paul Tetlock. I am deeply grateful to Robert for his insight and support. He has been always generous with his time and advice throughout my doctoral studies. I am grateful to Ross who posed many insightful questions and contributed valuable suggestions. I am also greatly indebted to Michael for his tireless insight, patience, and suggestions that have improved this dissertation immensely. I would like to thank my fellow Ph.D. students, especially Jenny Brown, Bill Mayew, Kirill Novoselov, and Neil Schreiber, for being such good friends and colleagues.

Finally, my deepest thanks go to my parents, my sisters, and my wife, for their unconditional love and support. They have been my source of strength. Without them this would not have been possible. 


\title{
Is Information Uncertainty Positively or Negatively Associated with Post-Earnings-Announcement Drift?
}

\author{
Publication No.
}

Joonho Lee, Ph.D.

The University of Texas at Austin, 2007

Supervisor: Robert N. Freeman

This dissertation reconciles ostensibly conflicting evidence from prior research about the association between information uncertainty and post-earningsannouncement drift (PEAD). According to traditional PEAD studies there should be a positive association between PEAD and uncertainty about the implication of an earnings announcement for future earnings, referred to in this dissertation as “information uncertainty." Empirical studies have documented both positive and negative associations, however. In particular, studies that use analyst forecast dispersion as a proxy for information uncertainty report a negative association between information uncertainty and PEAD. Although the authors of those studies argue that their results are consistent with behavioral finance theories, a negative association between information uncertainty and PEAD is troubling because it is not consistent with the notion that more reliable information improves market efficiency. In fact, previous empirical studies that use proxies for information uncertainty other 
than analyst forecast dispersion find a positive association between information uncertainty and PEAD.

This study argues that the negative association between analyst forecast dispersion and PEAD can be explained by "herding" behavior immediately after earnings announcements. I introduce an analyst-based proxy for information uncertainty that mitigates the effects of herding on forecast dispersion. I find that, after controlling for the effect of herding, there is a positive association between information uncertainty and PEAD even when analyst forecasts are used to measure information uncertainty. 


\section{Table of Contents}

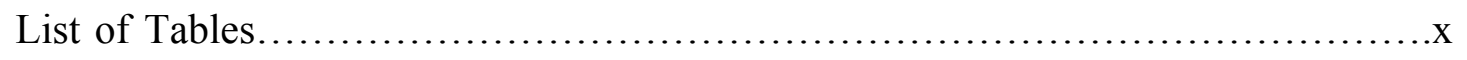

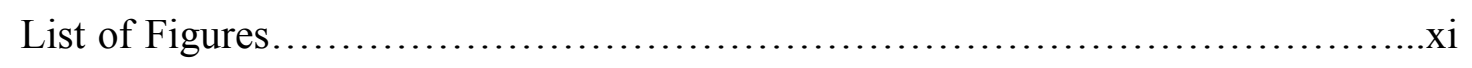

Chapter 1 Introduction...................................................

Chapter 2 Background and Prior Research.................................. 8

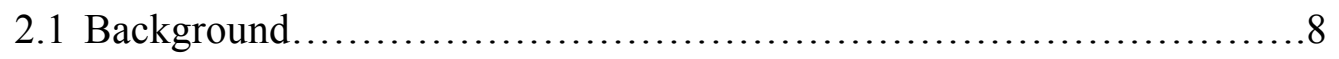

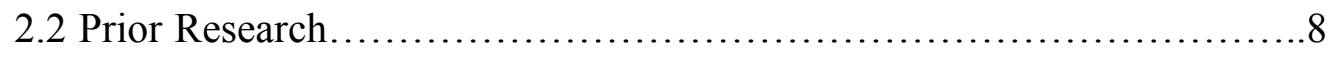

2.2.1 Conservatism Bias and the Relation between Information

Uncertainty and PEAD ................................ 8

2.2.2 Overconfidence about Private Information, Self-Attribution Bias, and the Relation between Information Uncertainty and PEAD..11

2.2.3 Analyst Forecast Dispersion and Information Uncertainty.....14

Chapter 3 Hypotheses Development......................................... 18

3.1 The Importance of Reconciliation of Prior Research............................18

3.2 Two Sources of Information: Public and Private.....................20

3.3 Analysts' Concern about Forecast Timeliness.......................21

3.4 Market Reaction to Earnings News and Analysts' Forecasts............22

3.5 Herding Behavior and Forecast Timeliness...........................24 Viii 
Chapter 4 Research Design and Sample Selection.

4.1 Research Design............................................28

4.2 Sample Selection......................................................

Chapter 5 Empirical Results.................................................. 35

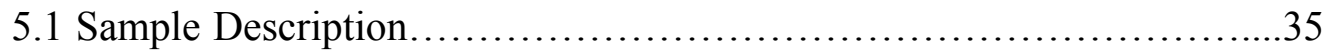

5.2 Test of Hypothesis 1: Sensitivity of Forecast Dispersion to the Market's Response................................................. 36

5.3 Test of Hypothesis 2: Difference of Forecast Dispersions between

Forecast Window $(0,5)$ and Forecast Window $(6,45) \ldots \ldots \ldots \ldots \ldots . \ldots 39$

5.4 Test of Hypothesis 3: Regression Result.............................44

Chapter 6 Supplemental Tests.......................................... 48

6.1 Forecast Error Based SUE versus Abnormal Return Based SUE..........48

6.2 Change in Information Uncertainty versus Level of Information Uncertainty.................................................. 49

6.3 Sub-sample Tests............................................50

Chapter 7 Summary and Conclusions.......................................53

Tables and Figures..................................................... 55

References............................................................ 77

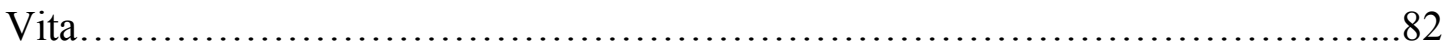




\section{List of Tables}

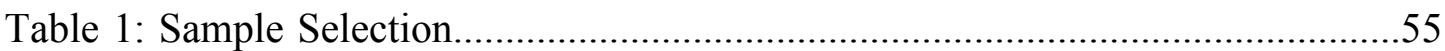

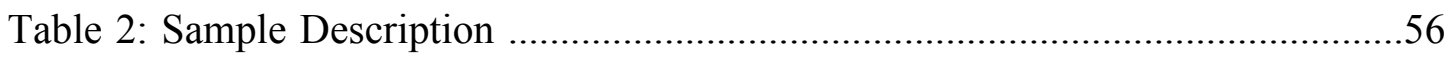

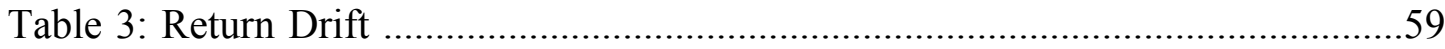

Table 4: Analyst Forecast Dispersion and Change of Information Uncertainty.......60

Table 5: General Pattern of Analyst Forecast Updating Behavior............................61

Table 6: Forecast Window $(0,5)$ versus Forecast Window $(6,45)$

- Forecast Dispersion and Change of Information Uncertainty.....................62

Table 7: Regression Tests of the Influence of Information Uncertainty on PEAD.....66

Table 8: Regression Tests of the Influence of Information Uncertainty on PEAD

- When SUE_RET is Used as an Earnings Surprise Measure.......................68

Table 9: Regression Tests of the Influence of Information Uncertainty on PEAD

- When Level of Uncertainty is Used Instead of Change of Uncertainty.....69

Table 10: Regression Tests of the Influence of Information Uncertainty on PEAD

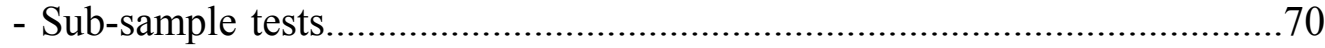

Table 11: Fama-MacBeth Regression Tests......................................72 


\section{List of Figures}

Figure 1: Overconfidence in Firm Value Estimation............................. 73

Figure 2: The Combination of Hypothesis 1 and Hypothesis 2..................... 74

Figure 3: Analysts' Forecasts and Forecast Horizons..........................74

Figure 4: Forecast Collection Timing...................................... 75

Figure 5: Changing Pattern of Analyst Forecast Dispersion and Change of

Uncertainty ................................................. 76 


\section{Chapter 1: Introduction}

One of the best known market anomalies is post-earnings-announcement drift (PEAD), which means that prices continue to move up after positive earnings surprises and down after negative earnings surprises. Since first documented by Ball and Brown (1968), many scholars have examined various explanations for PEAD. Although the debate is still ongoing, people seem to agree with several points. First, PEAD is regarded as a market underreaction, although people disagree on the causes of the underreaction. Second, the more information about firms the market has, the less likely PEAD is observed. Many empirical studies support the second point. For example, information increases and PEAD declines with firm size (Foster, Olsen, and Shevlin, 1984; Bernard and Thomas, 1989; Freeman and Tse, 1989). If firms are followed by more analysts, who expedite information flow in the market, or firms are held by more sophisticated institutions, firms have less PEAD (Hong, Lim, and Stein, 2000; Bartov, Radhakrishnan, and Krinsky, 2000). When firms provide additional information via conference calls, they are likely to have less PEAD (Kimbrough, 2005). All these examples show that even though the market is not perfectly efficient, it does utilize available information efficiently to some degree.

This research suggests, by extension, that PEAD increases with the "information uncertainty" created by an earnings announcement, when announcement-related uncertainty is derived from analyst forecast distribution of future earnings. However, a positive association between this form of "information 
uncertainty" and PEAD has not been consistently supported by prior empirical research.

Several recent studies that use analyst forecast dispersion as a proxy for information uncertainty report a counter-intuitive result. Specifically, Dische (2002) reports that higher abnormal returns can be achieved by applying an earnings momentum strategy to stocks with low forecast dispersion, i.e., forecast dispersion is negatively associated with PEAD. Similarly, when measuring change of analyst uncertainty surrounding quarterly earnings announcement dates (based on Barron et al.’s (1998) analyst forecast decomposition model), Liang (2003) finds that when analyst uncertainty following quarterly earnings announcements is lower than uncertainty prior to the announcement, there is more PEAD, i.e., a negative association between information uncertainty and PEAD. Both Dische (2002) and Liang (2003) ascribe their results to a behavioral finance theory which advances the notion that investors underweight new evidence and incompletely update their beliefs. Specifically, investors update their beliefs by too little with respect to more objective (i.e., less uncertain) information due to cognitive bias about the 'strength' and the 'weight' of new evidence (Barberis, Shleifer, and Vishny, 1998; Griffin and Tversky, 1992). ${ }^{1}$

In contrast to Dische (2002) and Liang (2003), Jiang, Lee, and Zhang (2005) use firm age, return volatility, trading volume, and duration of firm's future cash

\footnotetext{
${ }^{1}$ Detailed explanations follow in chapter 2.
} 
flows to proxy for information uncertainty and find evidence of a positive association between information uncertainty and PEAD. ${ }^{2}$ They argue that their results are consistent with a different behavioral finance theory which is based on investor overconfidence in their private information and self-attribution bias (Daniel, Hirshleifer, and Subrahmanyam, 1998). In particular, Jiang et al. (2005) argue that investor overconfidence about their private information worsens when information uncertainty is high. ${ }^{3}$

This study attempts to reconcile these conflicting empirical results. I argue that the negative association between information uncertainty and PEAD (as shown in Dische (2002) and Liang (2003)) is due to incorrect measurement of uncertainty about the implication of an earnings announcement for future earnings that is extracted from analysts' forecasts.

Extracting a measure of information uncertainty from analysts' forecasts is an appealing idea because analysts play an important role in the market as information intermediaries (Schipper, 1991; Lang and Lundholm, 1996). However, analysts' forecasts are influenced by their strategic decisions (Trueman, 1994; Hong, Kubik, and Solomon, 2000). For example, Trueman (1994) posits that analysts' forecasts do not necessarily reflect their best judgment due to "herding" behavior following the release of important price-relevant information, such as earnings. This means that

\footnotetext{
${ }^{2}$ Duration is a measure of implied equity duration introduced by Dechow, Sloan, and Soliman (2004), and it measures how long it takes for the price of a stock to be repaid by its internal cash flows.

${ }^{3}$ Although Liang (2003) uses "analyst uncertainty" and Jiang et al. (2005) "information uncertainty" respectively, those two uncertainties do not seem distinguishable. In this study, information uncertainty is used as the same meaning as analyst uncertainty or earnings uncertainty.
} 
when low forecast dispersion is driven by analyst herding behavior, the observed relation between forecast dispersion and the level of information uncertainty may be misleading. Furthermore, if analysts are more likely to herd when they are not sure about the information that they possess (i.e., when information uncertainty is high), low dispersion is in fact associated with high information uncertainty.

Several recent studies investigate the influence of uncertainty about future earnings on analysts' forecasts (Miller and Sedor, 2006; Alti, Kaniel, and Yoeli, 2006). Miller and Sedor (2006) find that when uncertainty about future earnings is high, analyst forecast revisions are influenced by observed stock price changes. Alti, Kaniel, and Yoeli (2006) analytically show that when investors face uncertainty about their private information, they wait for subsequent confirming news from the market. Following these studies, I hypothesize and find that for firms with large earnings surprises, analyst forecast dispersion is lower for firms with confirming abnormal returns than for firms without confirming abnormal returns.

Clement and Tse (2003) also provide an insight about the influence of analysts' motivation on analyst forecast dispersion. They find that investors care not only about forecast accuracy but also about the timeliness of forecasts. Therefore, I assume that when analysts are under time pressure, they are more likely to herd than to fully utilize their own judgment.

Examining the pattern of analyst forecast updating behavior, I find that about half of forecast revisions are made by the end of the third day after an earnings 
announcement, which suggests that analysts do care about forecast timeliness. Moreover, analyst forecast dispersion is much smaller for forecasts reported within five days following an earnings announcement (forecast window $(0,5))$ than when forecasts are collected at later dates (forecast window $(6,45)$ ), although each forecast group has similar numbers of forecasts. I argue that this pattern of analyst forecast dispersion should be considered when forecast dispersion is used to measure information uncertainty. I argue that a better measure of information uncertainty is obtained by using analyst forecasts updated late after an earnings announcement.

Like Liang (2003), I operationalize information uncertainty by Barron et al.'s (1998) measurement of analyst uncertainty, which is squared error in individual forecasts averaged across analysts, assuming that high uncertainty is associated with large forecast errors. Barron et al. (1998) find that forecast dispersion is not a perfect measure of analyst uncertainty and analyst uncertainty can be measured more precisely by considering forecast errors and the number of forecasts. ${ }^{4}$ My final measure of information uncertainty is change in analyst uncertainty measured by subtracting post-announcement analyst uncertainty from pre-announcement analyst uncertainty. I use change in uncertainty because the phenomenon I am trying to measure is the incremental effects of earnings announcements on the uncertainty of future earnings.

\footnotetext{
${ }^{4}$ Detailed explanations follow in chapter 2.
} 
Once I use late forecast updates (i.e., forecast window $(6,45))$ and calculate the change in uncertainty, I find that change in uncertainty is positively (not negatively) associated with PEAD, i.e., when information uncertainty is higher, there is more post-earnings-announcement drift. In contrast, when immediately updated forecasts are used (i.e., forecast window $(0,5))$, change in uncertainty and PEAD are negatively associated, which is consistent with Liang (2003). Therefore, I conclude that the negative association between information uncertainty and PEAD is caused by incorrect forecast collection timing. Additionally, when using abnormal returns surrounding earnings announcements as an alternative earnings surprise measure (instead of forecast errors), I find a stronger positive association between information uncertainty and PEAD. This result also supports my expectation that analyst forecast dispersion is sensitive to the market's response to earnings surprises (i.e., analysts forecasts are influenced by confirming or non-confirming news from the market), and therefore using abnormal returns surrounding earnings announcements, which is used as an alternative earnings surprise measure in previous studies, can provide a more accurate relation between analyst forecast dispersion and PEAD.

This study is important because it reconciles two conflicting empirical results and answers why there has been a disagreement. The supporting evidence of the positive association between information uncertainty and PEAD is important because it strengthens the argument that reducing information uncertainty improves market efficiency, i.e., the benefits of more reliable or more objective information to the 
market. The validity of this intuitive notion would be questioned if the negative association between information uncertainty and PEAD were supported. This study also contributes to the literature about analysts' forecasts by showing that it could be problematic to naively use analyst forecast dispersion as an information uncertainty measure. Analyst forecasts need to be carefully collected (i.e., collection timing matters) and decomposed (as in Barron et al. (1998)) to properly represent the level of information uncertainty.

The remainder of this dissertation is organized as follows. Chapter 2 provides a literature review about the association among information uncertainty, analyst forecast dispersion, and PEAD. Chapter 3 presents the research questions and hypotheses. Chapter 4 explains the research design and outlines the sample collection process. Chapter 5 discusses the empirical results. Chapter 6 then discusses the supplemental tests, and chapter 7 concludes. 


\section{Chapter 2: Background and Prior Research}

\subsection{Background}

One of the most puzzling market anomalies is PEAD, which reflects the fact that investors fail to incorporate predictable future earnings using publicly available current earnings information. Despite numerous studies that have examined various explanations for PEAD, there is no dominant theory to explain what causes PEAD, and the debate is still ongoing. More recently, behavioral finance researchers have discussed investors' cognitive biases, which may lead to misinterpretation of earnings information, as possible causes of PEAD (e.g., Barberis, Shleifer, and Vishny, 1998; Daniel, Hirshleifer, and Subrahmanyam, 1998; Hong and Stein, 1999). In this chapter, I review several behavioral finance theories and perspectives of these theories about the relation between information uncertainty and PEAD.

\subsection{Prior Research}

\subsubsection{Conservatism Bias and the Relation between Information Uncertainty and PEAD}

Barberis, Shleifer, and Vishny (1998) ascribe PEAD to conservatism bias. They claim that PEAD is explained by the theory that people rely too much on their priors, while paying too little attention to new information, i.e., people are slow to change their beliefs in the face of new evidence (Edwards, 1968). For example, when 
good earnings news occurs, investors underestimate the positive effect of the good news.

Barberis et al.'s (1998) PEAD explanation is also partly based on Griffin and Tversky (1992), who claim that people update their beliefs based on the "strength" and the "weight" of new evidence. Strength refers to such aspects of the evidence as salience and extremity, whereas weight refers to statistical informativeness, such as sample size. According to Griffin and Tversky (1992), people focus too much on the strength of the evidence, while underestimating its weight, relative to a rational Bayesian, when revising their forecasts. ${ }^{5}$ Based on Griffin and Tversky (1992), Barberis et al. (1998) argue that investors seem to underweight information in quarterly earnings announcements, because a single earnings number can be regarded as weak information without any particular pattern or strength of its own. In doing so, investors ignore the substantial weight that the latest earnings news has for forecasting the level of future earnings. Therefore, investors underreact to quarterly earnings announcements.

The work of Bloomfield, Libby, and Nelson (2000) is also related to the 'strength and weight' story. They show that prices tend to overreact to unreliable information and underreact to highly reliable information because investors' confidence in information is moderated toward a central level. They refer to this

\footnotetext{
${ }^{5}$ The "weight" of the information could be interpreted as "credibility."
} 
phenomenon as "moderated confidence" because investor confidence is moderated toward an average level that is insufficiently high or low.

A recent study by Liang (2003) examines the relation between PEAD and the cognitive bias about strength and weight. She assumes that the level of the quarterly earnings surprise corresponds to the strength of the information, and that changes in forecast errors around earnings announcements correspond to the weight of the information. Liang (2003) assumes that when analysts are uncertain about a firm's future performance, they tend to have larger forecast errors. She also argues that a large decrease in forecast errors after an earnings announcement implies a large decrease in analyst uncertainty, and the decrease in analyst uncertainty means that analysts receive very reliable new information.

Liang (2003) finds that when holding the level of earnings surprise constant, firms with larger decreases in forecast errors have larger PEAD. She argues that this result is caused by the fact that underreaction is amplified under the high weight (or very reliable information) situation. In other words, investors underreact to quarterly earnings surprises that provide very reliable information about future earnings. This underreaction is due to cognitive bias, which does not let investors fully appreciate the credibility (or the weight) of the earnings surprise.

Similar to Liang (2003), Dische (2002) also shows that there is more PEAD when analyst forecast dispersion is low than when analyst forecast dispersion is high. He claims that this result supports the idea that investors focus too little on the weight 
of new evidence, and update their beliefs in the right direction too conservatively. Furthermore, investors update their beliefs by too little with respect to more objective (reliable) information. If analyst forecast dispersion is regarded as a proxy for information uncertainty (e.g., Imhoff and Lobo, 1992; Barron and Stuerke, 1998; Clement, Frankel, and Miller, 2003), this result might indicate that information uncertainty and PEAD are negatively associated. In sum, the results reported by Dische (2002) and Liang (2003) suggest a negative association between information uncertainty and PEAD.

\subsubsection{Overconfidence about Private Information, Self-Attribution Bias, and the Relation between Information Uncertainty and PEAD}

According to a different stream of behavioral finance theory, the association between PEAD and information uncertainty is claimed to be positive. This theory posits that investors overestimate the precision of their own information signals (Odean, 1998; Daniel, Hirshleifer, and Subrahmanyam, 1998, 2001). Specifically, Daniel et al. (1998) suggest that overconfidence about the precision of private information and self-attribution bias are driving forces of PEAD. Daniel et al. (1998) claim that investors underestimate the information content of important public news such as quarterly earnings announcements, while too heavily relying on their private information. Overconfidence about their private information is strengthened by a self-attribution bias. For example, when initial investment positions are confirmed by 
the market, investors draw on self-attribution bias to ascribe their success to their ability. Conversely, when investment positions result in losses, investors blame bad luck or environmental factors which are beyond their control.

Motivated by Daniel et al. (1998), Jiang, Lee, and Zhang (2005) find that there is more PEAD when information uncertainty is high. Jiang et al. (2005) propose three observations to support the positive relation between uncertainty and PEAD. First, they state that under Daniel et al.'s overconfidence theory, there is a difference between the true distribution of firm value estimates and overconfident investors' distribution of firm value estimates. Specifically, overconfident investors have narrower distributions of firm values. Moreover, Jiang et al. (2005) claim that high information uncertainty firms have more diffused (or flatter) distributions of value estimates than firms with low information uncertainty. This means that differences between the true distributions of firm values and overconfident investors' distributions are greater for high information uncertainty firms than for low information uncertainty firms. Figure 1 illustrates the difference between an investor's distribution and the true distribution for a low (Panel A) and a high (Panel B) information uncertainty firm. In other words, Jiang et al. (2005) assume that investors cannot adjust the distribution of value estimates along with the change of uncertainty level. Therefore, overconfidence bias is exacerbated for high uncertainty firms. 
Second, Jiang et al. (2005) also claim that for high information uncertainty firms, the quality of investors' private information is more difficult to assess. In other words, there is less feedback from the market for high information uncertainty firms than for low information uncertainty firms. Therefore, it takes more time for the market to learn the quality of investors' private information and for price to reach the true value. Third, Jiang et al. (2005) argue that high information uncertainty firms tend to be "story stocks," in which otherwise reliable public signals look noisy, and private signals appear more plausible. Therefore, investors are more likely to be influenced by rumors, and are more likely to speculate on the value of the stocks than to evaluate firms objectively. In sum, all three characteristics that are related to high information uncertainty make it difficult for investors to assess the true value of the firm. Therefore, it takes more time for stock prices to arrive at true values when information uncertainty is high, i.e., there is more PEAD. Jiang et al. (2005) show this result when they use firm age, return volatility, trading volume, and the duration of the firm's future cash flows as proxies for information uncertainty.

In summary, empirical results based on two different behavioral finance theories collide with respect to the relation between PEAD and information uncertainty. Both Dische (2002) and Liang (2003) argue that investors' underreaction is exacerbated when information is more credible, i.e., when information uncertainty is low. In other words, they find that low information uncertainty brings more PEAD than high information uncertainty. In contrast, Jiang 
et al. (2005) argue that high information uncertainty exacerbates overconfidence bias, and report that high information uncertainty brings more PEAD than low information uncertainty. My study attempts to reconcile these conflicting results.

\subsubsection{Analyst Forecasts Dispersion and Information Uncertainty}

In accounting research, analyst forecast dispersion is popularly measured using the standard deviation of analysts' forecasts. Some studies use the standard deviation of analysts' forecasts as a proxy for earnings uncertainty (e.g., Imhoff and Lobo, 1992; Clement, Frankel, and Miller, 2003), assuming that the standard deviation reflects uncertainty about the future economic performance of a firm. This assumption seems to fit with one's intuition at first glance. However, besides information uncertainty, analyst forecast dispersion is also influenced by disagreement among analysts due to their own private information.

Based on the assumption that each analyst observes two signals about future earnings - one public (common across all analysts) and one private (idiosyncratic to each analyst) - Barron, Kim, Lim, and Stevens (1998) provide a more detailed and comprehensive picture about the relations among forecast dispersion, errors in the mean forecast, analyst uncertainty, and consensus (that is, the degree to which analysts share a common belief). Instead of simply regarding forecast dispersion as a proxy for uncertainty, they show uncertainty can be measured by combining forecast dispersion, error in the mean forecast, and the number of forecasts. 
Barron et al. (1998) disaggregate analyst forecast dispersion into uncertainty and heterogeneous information, which is a reverse of consensus. Moreover, they show that forecast dispersion is an increasing function of uncertainty but a decreasing function of consensus:

$$
D=V(1-\rho),
$$

where $D$ is dispersion, $V$ is analyst uncertainty, and $\rho$ is a measure of consensus.

The degree of consensus, which is denoted by $\rho$, is the correlation in forecast errors across analysts, and it estimates how much the average (mean) belief reflects common versus private information. When all available information is common, all analysts' beliefs are identical and $\rho=1$. As $\rho$ approaches zero, the amount of private information rises and analysts' beliefs diverge more from the average belief. Thus, they use $(1-\rho)$ to proxy for the amount of private information or heterogeneous information among analysts.

On the other hand, analyst uncertainty, which is another component of analyst forecast dispersion and noted as $V$, is the squared error in individual forecasts averaged across analysts. This is based on the fact that when analysts are uncertain about a firm's future performance, they tend to have larger forecast errors. The following equations show measures of heterogeneous information and uncertainty according to Barron et al. (1998). Dispersion $(D)$ in analysts' forecasts is calculated as the sample variance of forecasts, 


$$
D=\frac{1}{N-1} \sum_{i=1}^{N} E\left(f_{i}-f\right)^{2},
$$

where $f_{i}$ is the earnings forecast by analyst $i, f$ is the mean forecast across analysts, and $N$ is the number of forecasts. $S E$ is defined as the squared error in the mean forecast,

$$
S E=(y-f)^{2}
$$

where $y$ is the actual earnings and $f$ is the mean forecast. Barron et al. (1998) finally show that consensus $(\rho)$ and analyst uncertainty $(V)$ can be expressed by using properties of the available earnings forecast data: ${ }^{6}$

$$
\begin{aligned}
& \rho=\frac{S E-D / N}{(1-1 / N) D+S E}, \\
& V=\left(1-\frac{1}{N}\right) D+S E
\end{aligned}
$$

I take away two insights from Barron et al. (1998). First, the use of simple forecast dispersion as a proxy for information uncertainty is not perfect, and information uncertainty can be measured more precisely by also considering forecast errors and the number of forecasts. Second, the timing of forecast collection matters when measuring forecast dispersion and/or forecast errors because the influence of public and private information on analysts' forecasts varies over time. For example, a forecast that is made immediately after an earnings announcement is heavily based on announced public earnings news, while a forecast that is made quite awhile after

\footnotetext{
${ }^{6}$ See Barron et al. (1998) for proofs and detailed explanations.
} 
the earnings announcement is more likely to be influenced by private information than the public earnings news.

I believe that the latter insight that I draw from Barron et al. (1998) - that the timing of forecast collection matters - is an important issue, but it has been neglected in prior research. For example, although Liang (2003) uses Barron et al.'s (1998) methodology to measure the information uncertainty surrounding quarterly earnings announcements, she does not consider that forecasts that are made before the earnings announcement might have very different characteristics from the forecasts which are made immediately after the earnings announcement - she chose latest forecast within forecast window $(-45,-1)$ for pre-announcement forecasts and chose first forecast within forecast window $(1,30)$ for post-announcement updated forecasts, where 0 is the quarterly earnings announcement date. ${ }^{7}$ I continue to discuss this issue in the following chapter.

\footnotetext{
${ }^{7}$ Although she used forecast window of $(1,30)$ for the post-announcement forecasts, the majority of forecasts are made immediately after the earnings announcement. See Table 5.
} 


\section{Chapter 3: Hypotheses Development}

\subsection{The Importance of Reconciliation of Prior Research}

The previous chapter presented two opposing explanations about the relation between information uncertainty and PEAD, and selected prior empirical results support each explanation. I attempt to reconcile the conflicting empirical results, and this is an important issue for several reasons. First, a negative relation between information uncertainty and PEAD runs counter to the widely held belief that more objective (or more reliable) information increases market efficiency. Prior empirical studies show that large firms, which disclose more information than small firms, have less PEAD (Foster et al., 1984; Bernard and Thomas, 1989; Freeman and Tse, 1989). PEAD declines with the level of institutional holdings (Bartov, Radhakrishnan, and Krinsky, 2000). Firms providing additional information using conference calls are reported to have less PEAD (Kimbrough, 2005). If large firms, firms favored by institutions, and firms providing conference calls have lower information uncertainty (i.e., the uncertainty about the implication of an earnings announcement for future earnings is lower) than small firms, firms avoided by institutional investors, and firms without conference calls, then prior evidence that PEAD decreases with information uncertainty seems puzzling. ${ }^{8}$

\footnotetext{
${ }^{8}$ Although indirectly related to PEAD, many studies also show that individual firms benefit from lowering information uncertainty. For example, Botosan (1997) finds that high level of disclosure reduces cost of capital. Francis, LaFond, Olsson, and Schipper $(2004,2005)$ find that high quality earnings (or accruals) reduce cost of capital. Therefore, the argument that low information uncertainty increases PEAD can be interpreted as indicating that low information uncertainty is good for individual firms but bad for market efficiency. This interpretation also seems counter-intuitive.
} 
Second, this study provides insight on why PEAD exists. If information uncertainty and PEAD are positively associated, Daniel et al.'s (1998) and Jiang et al.’s (2005) explanation (which attributes PEAD to overconfidence in private information and self-attribution) is supported by the evidence. In contrast, if information uncertainty and PEAD are negatively associated, Barberis et al. (1998) and Griffin and Tversky (1992)'s theory (which attributes PEAD to conservatism bias and bias about 'strength and weight') seems to be supported by the evidence. ${ }^{9}$ Although showing the positive or negative relation is not sufficient to fully answer what drives PEAD, it moves us closer to understanding the reason(s) PEAD exists.

In this study, I claim that the conflicting results noted above are due to inappropriate proxies for information uncertainty used in Dische (2002) and Liang (2003). Dische (2002) uses analyst forecast dispersion itself, ${ }^{10}$ and Liang (2003) uses Barron et al.'s (1998) model to measure analyst uncertainty. I argue that neither of the studies is successful in extracting information uncertainty from analysts' forecasts. This failure to correctly measure information uncertainty leads to an incorrect negative association between information uncertainty and PEAD.

\footnotetext{
${ }^{9}$ This statement is valid only when the uncertainty measure is an appropriate proxy for the 'weight' of new evidence. Whether Dische (2002) and Liang (2003) properly operationaize the weight of new evidence is an issue, which is not covered in this study. If the uncertainty measure is not a good proxy for the weight of new evidence, the positive association between uncertainty and PEAD (which is the finding of this study) cannot reject the PEAD explanations of Barberis et al. (1998) and Griffin and Tversky (1992).

${ }^{10}$ Although Dische (2002) adheres to the terminology of 'dispersion in analyst forecasts,' he also states that dispersion can serve as a proxy for earnings uncertainty (pp. 221).
} 
Specifically, neither study considers the fact that the characteristics of analysts' forecasts change drastically over time.

\subsection{Two Sources of Information: Public and Private}

There are several reasons why the timing of forecast collection matters when information uncertainty is measured using analysts' forecasts. First, as Barron et al. (1998) identify, analysts have two sets of information; one is public information, and the other is private. The influence of each information set on analysts' forecasts changes over time. Liang (2003) compares the latest earnings forecasts made within forty five days before the earnings announcement with the first forecasts made within thirty days after the earnings announcement to measure information uncertainty. She examines the change of forecast errors between the two forecast groups, and she argues that analyst uncertainty declines as forecast errors decrease. However, I argue that Liang's comparison forecast groups are an inappropriate match. The forecasts made before the earnings announcement incorporate all the available public and private information because those forecasts are made at least a month after the previous quarterly earnings announcement. In contrast, the forecasts made immediately after earnings announcements are heavily influenced by the interpretation of public information. One may argue that the forecasts after earnings announcements reflect all the public and private information available. However, I expect that the influence of the private information is minimal immediately after 
major public announcements such as earnings announcements. Therefore, I expect that analyst forecast dispersion measured immediately after an earnings announcement will be much lower than analyst forecast dispersion measured before the earnings announcement. ${ }^{11}$

\subsection{Analysts' Concern about Forecast Timeliness}

Another reason why the timing of forecast collection matters is that analysts may try to provide timely forecasts even at the cost of forecast accuracy. Clement and Tse (2003) find that investors value forecast timeliness in addition to forecast accuracy. Therefore, it is difficult to deny that analysts, who have investors as their customers, pay attention to timeliness of their forecasts. Analysts may sacrifice forecast accuracy to make timelier forecasts. If this is true, analysts' forecasts made before an earnings announcement, which are motivated primarily by forecast accuracy, are not fully compatible with the forecasts made immediately after the earnings announcement, which are more likely to be motivated by timeliness.

\footnotetext{
${ }^{11}$ Shortened forecast horizon is another reason to lower analyst forecast dispersion. However, I expect that the influence of the public announcement on forecast dispersion is greater than the influence of the shortened forecast horizon. In fact, I find that the dispersion of analysts' forecasts made several days after an earnings announcement (using forecast window $(6,45)$ ) is higher than the dispersion of analysts' forecasts made immediately after the earnings announcement (using forecast window $(0,5)$ ), even though the forecast horizon is shorter. See Table 6 and Figure 5.
} 


\subsection{Market Reaction to Earnings News and Analysts’ Forecasts}

Finally, I claim that abnormal returns surrounding earnings announcements, which are the market's initial response to the earnings news, influence analysts' forecasts, and I argue that this influence is greater when the forecasts are made soon after earnings announcements.

My assertion about the influence of the abnormal returns on analysts' forecasts stems from recent studies that investigate why investors and analysts chase return trends (Alti, Kaniel, and Yoeli, 2006; Miller and Sedor, 2006). Alti et al. (2006) analytically show that when investors face uncertainty about their private information, they wait for subsequent confirming news from the market before establishing a stock position. Through their experiment, Miller and Sedor (2006) also obtain supportive results: when uncertainty about future earnings is high, analysts' earnings forecast revisions are influenced by observed stock price changes.

The results from these studies (Alti, et al., 2006; Miller and Sedor, 2006) shed light on the relation between earnings surprises and analysts' forecasts. When earnings surprise is measured by the difference between announced earnings and the mean analysts' forecast, a big earnings surprise means that analysts have not made accurate earnings predictions. Possible explanations for this large forecast error include that analysts missed some important public information or they did not have good private information. In either explanation, big earnings surprises reflect an inability to make accurate forecasts. 
What would rational analysts do when encountering a large difference between their earnings forecast and actual earnings? Following Alti et al. (2006) and Miller and Sedor (2006), I infer that analysts are more likely to pay attention to the market's response to the earnings surprise than otherwise. Therefore, analyst forecast revisions are more likely to be influenced by abnormal returns surrounding earnings announcement dates. Specifically, I hypothesize that when the market confirms a large earnings surprise, there is smaller forecast dispersion than otherwise.

This observation is important because even though true analyst uncertainty of big earnings surprise firms might be the same, the calibrated analyst uncertainty could be different if analyst forecast dispersion is used as a proxy for information uncertainty. ${ }^{12}$ In summary, I argue that the influence of the abnormal returns surrounding earnings announcement dates on analyst forecast revisions may distort the true information uncertainty to which investors are exposed.

The first hypothesis is the summary of my last assertion about the relation between abnormal returns surrounding earnings announcements and analyst forecast dispersion.

\footnotetext{
${ }^{12}$ This argument is a complement of previous research by Morse, Stephen, and Stice (1991). Morse et al. (1991) show that there is greater forecast dispersion when the difference between announced earnings and forecasted earnings is larger. However, I expect that not all the large earnings surprise firms have large forecast dispersion, and that if the market confirms the large earnings surprise, there is smaller forecast dispersion than otherwise. In other words, forecast dispersion of large earnings surprise firms depends on the market's response to the news.
} 
H1: When large earnings surprises occur (based on forecast errors), analyst forecast dispersion is lower for firms with confirming abnormal returns surrounding the earnings announcement than for firms without confirming abnormal returns.

\subsection{Herding Behavior and Forecast Timeliness}

The next hypothesis deals the relation between the timing of the data collection and analyst forecast dispersion more directly. I have argued that comparisons of analysts' forecasts made before earnings announcements and forecasts made immediately after earnings announcements may lead to biased measures of information uncertainty. To overcome this problem and match the comparison groups of analysts' forecasts, I designed an alternative measure of information uncertainty - instead of using analysts' forecasts made immediately after earnings announcements, I collected analysts' forecasts at least five days after earnings announcements.

My "late forecast" measure could be influenced by analysts' "herding" behavior (Trueman, 1994), however. Trueman (1994) and many other following studies (Hong, Kubik, and Solomon, 2000; Clement and Tse, 2005) show that analysts have a motivation not to reveal their own private information but to demonstrate herding behavior. In these studies, later forecasts are more likely to be affected by herding, and the first movers are more likely to use their private information in predicting future earnings of the firm. 
I claim, however, that early forecasts right after the earnings announcement may not necessarily be based on analysts' private information. First, the early forecasts could be the result of the heavy influence of public earnings information, i.e., earnings news is weighted too much, while private information is weighted too little. Second, early forecasts could be the result of analysts' reliance on the market's response to the earnings news, which is more likely to happen when the difference between forecasted earnings and actual earnings is large, as discussed earlier. Third, early forecasts after earnings announcements could be the result of merely following the forecasts made one or two days earlier by other analysts. I call this "early herding" to distinguish it from the original herding behavior proposed by previous studies. These three examples would cause lower dispersion of early forecasts than of late forecasts. Note that as posited in Barron et al. (1998), analyst forecast dispersion is one of the variables that determine the level of information uncertainty. ${ }^{13}$ Therefore, a failure to consider the changing pattern of the forecast dispersion would result in a biased measure of information uncertainty.

I expect that if analysts feel pressure to make timely forecasts, as I inferred from Clement and Tse (2003), analysts' forecasts are more likely to be made by following one or more of these examples than to be made by using their private information. The analysts' strategy of following the above-mentioned examples,

\footnotetext{
${ }^{13}$ Strictly speaking, Barron et al.'s (1998) analyst uncertainty measure is squared error in individual forecasts averaged across analysts. However, this measure is indeed influenced by analyst forecast dispersion.
} 
instead of following their own private information, seems to be rational, especially to the analysts who are able to update their forecasts later without being penalized for earlier inaccurate forecasts. Overall, I conclude that analysts' strategic forecasting decisions cause forecast updates soon after earnings announcements to be inappropriate measures of information uncertainty.

In contrast, forecasts updated several days after earnings announcements are more likely to be the result of full incorporation of public and private information and are more likely to be free from the market's response and "early herding" behavior. In summary, I expect that the dispersion of the late updated forecasts will be larger than the dispersion of the early updated forecasts. Based on discussions so far, my second hypothesis can be formally stated as follows:

H2: The dispersion of the analysts' forecasts updated immediately after earnings announcements is lower than the dispersion of the analysts' forecasts updated several days after earnings announcements.

Figure 2 summarizes and contrasts hypothesis 1 and hypothesis 2 . The last column of the figure indicates the effects of confirming versus non-confirming returns on forecast dispersion (hypothesis 1), and the last row depicts the effects of forecast timing on forecast dispersion (hypothesis 2).

Finally, I examine the relation between PEAD and information uncertainty measured through analysts' forecasts. As discussed above, I argue that previous 
research has failed to consider analysts' motivations to follow environmental factors, such as the market's response to earnings news and the early herding, rather than using their own private information. To control for these factors, I propose that late updated forecasts provide more accurate measures of information uncertainty than early updated forecasts. I suspect that use of early updated forecasts distort the true relation between information uncertainty and PEAD. I hypothesize that PEAD is positively associated with information uncertainty, after controlling for the factors that distort information uncertainty measured using early analysts' forecasts.

H3: There is a positive association between information uncertainty and $P E A D$, i.e., firms with higher information uncertainty have more PEAD than firms with lower information uncertainty. 


\section{Chapter 4: Research Design and Sample Selection}

\subsection{Research Design}

The basic research design of this paper is the same as Liang (2003)'s, but I modify the design to control for the factors that contaminate analysts' forecasts as a measure of information uncertainty. I apply Barron et al.'s (1998) analytic framework to measure information uncertainty $(V)$, using three variables: forecast dispersion, mean forecast error, and number of forecasts.

$$
V=\left(1-\frac{1}{N}\right) D+S E
$$

where $D$ is the sample variance of the forecasts, $S E$ is the squared error of the mean forecast, and $N$ is the number of forecasts. I use the change in information uncertainty $(\triangle V)$ as the measure of the information uncertainty associated with an earnings announcement, where $\Delta V$ is information uncertainty after the earnings announcement ( $V$ _after) minus information uncertainty before the earnings announcement ( $V \_$before).

I do not use fixed point forecasts because they do not consider the idiosyncratic differences of information uncertainty among firms. In other words, certain firms have higher information uncertainty than other firms, making it more difficult for analysts to predict the firms' future earnings. For example, firms that have just begun their businesses or firms in high-tech industries are likely to have higher information uncertainty than firms that are at a mature stage in the business 
cycle or firms in relatively stable industries. Through change in information uncertainty, I control for this firm specific information uncertainty and measure the extent to which information environment is affected by the quarterly earnings announcement. $^{14}$

One-year and two-year-ahead annual earnings forecasts are used for the calculation of forecast dispersion $(D)$, mean forecast error $(S E)$, and the number of forecasts $(N)$ as in Liang (2003). One-year-ahead annual earnings forecasts are used for the calculations surrounding the first-, second-, and the third-quarter earnings announcements. Two-year-ahead annual earnings forecasts are used for the calculation before the fourth-quarter earnings announcement and one-year-ahead annual earnings forecasts are used for the calculation after the fourth-quarter earnings announcement. For example, one-year-ahead annual forecasts made before the first quarterly earnings announcement are used for the calculation of $V \_$before, and the one-year-ahead annual earnings forecasts made after the first quarterly earnings announcement are used for the calculation of $V_{-}$after. The same procedure is applied through the third quarterly earnings announcement. Two-year-ahead annual earnings forecasts made before the fourth quarterly earnings announcement are used for the calculation of $V$ _before, but one-year-ahead annual earnings forecasts made after the fourth quarterly earnings announcement are used for the calculation of $V \_$after.

\footnotetext{
${ }^{14}$ I also conducted tests using the level of uncertainty (i.e., fixed point forecasts) instead of the change of uncertainty. The level of uncertainty also showed a positive association with PEAD but only in a limited situation, which is discussed more in the supplemental tests chapter.
} 
Figure 3 illustrates analysts' forecasts and forecast horizons used for the research design.

Using one-year-ahead and two-year-ahead earnings forecasts is a compromise of theoretical correctness and practical feasibility. Theoretically, long-term forecasts are more price relevant than short-term forecasts (Liu and Thomas, 2000; Frankel and Lee, 1998). However, long-term forecasts such as three- to five-year-ahead annual earnings forecasts or long-term growth rate forecasts are not updated very often. In contrast, quarterly earnings forecasts are frequently updated but are less value relevant. Therefore, I use one-year-ahead and two-year-ahead annual earnings forecasts, which are not too short sighted and are frequently updated by analysts. I compare two different measures of standardized earnings surprise $(S U E)$. One is measured by analysts' forecast errors, which is the difference between reported quarterly earnings and the mean of the quarterly earnings forecasts made within forty five days before the earnings announcement; this is denoted by $S U E \_A F E$. I use the most recent forecast if the same analyst updates quarterly earnings forecasts within the forty-five day period. The difference is scaled by the closing stock price on the forty-fifth day before the earnings announcement. If the number of quarterly earnings forecasts made for firm-quarters is less than two, the firm-quarters are dropped from the sample. If the stock price on the forty-fifth day before the earnings announcement is lower than $\$ 1.00$, the firm-quarters are also 
excluded from the sample. ${ }^{15}$ My other standardized earnings surprise is cumulative three-day abnormal returns surrounding a quarterly earnings announcement date $(-1,1)$; this is denoted by $S U E \_R E T$. The daily abnormal return for firm $j$ on day $t$ $\left(A R_{j t}\right)$ is computed as the difference between the daily return of firm $j$ and the mean return of a firm-size decile that firm $j$ is a member:

$$
A R_{j t}=R_{j t}-R_{p t}
$$

where $R_{j t}$ is the daily raw return for firm $j$ on day $t$ and $R_{p t}$ is the equally weighted mean return on day $t$ of the NYSE/AMEX/NASDAQ firm size decile.

For $V \_$before measurement, I use annual earnings forecasts made within forty five days before quarterly earnings announcements. If the same analyst makes several forecasts in the period, the latest forecast is used for the measurement. For $V \_$after measurement, I use annual earnings forecasts made within forty five days after quarterly earnings announcements. However, annual earnings forecasts made during the first five days after announcement dates are not used for the sample. The reason not to use the first five-day forecasts (i.e., early updated forecasts) is explained in Chapter 3. Again, if the same analyst updates forecasts more than once in the period, the latest forecast is used for the $V$ after measurement, and the measurement is scaled by the closing stock price on the forty-fifth day before the earnings announcement. Figure 4 illustrates forecast collections around quarterly earnings announcement dates.

\footnotetext{
${ }^{15}$ As a sensitivity analysis, I tested a minimum of $\$ 5.00$, and the result was almost identical with $\$ 1.00$ minimum case.
} 
To test the hypothesis about the relation between information uncertainty and PEAD, I use a regression model with interaction terms, similar to the model used in Bhushan (1994), and Bartov, Radhakrishnan, and Krinsky (2000). The interaction terms indicate whether the interacted variables have incremental effects on PEAD in addition to standardized earnings surprise.

$C A R_{-} 2_{-} 60_{j q}=\beta_{0}+\beta_{1} S U E_{-} A F E_{j q}+\beta_{2} \Delta V_{j q} \times S U E_{-} A F E_{j q}+\sum_{i=3}^{N} \beta_{i} C O N T R O L_{j q i} \times S U E_{-} A F E_{j q}+\varepsilon_{j q}$,

where CAR_2_60 jq is abnormal returns accumulated from day 2 to day 60 for the firm $j$ after $q$ quarterly earnings announcement. ${ }^{16} S U E_{-} A F E_{j q}$ is the firm $j$ 's standardized unexpected earnings measured by analysts' forecast errors at the quarter $q$ earnings announcement. $\Delta V_{j q}$ is the firm $j$ 's change of information uncertainty around its quarter $q$ earnings announcement, and $C O N T R O L_{j q i}$ represents control variables that prior research has found to affect PEAD.

\subsection{Sample Selection}

I collected both quarterly and annual earnings forecasts from the Institutional Brokerage Estimate System (I/B/E/S) from 1989 to 2005 . I chose 1989 as the first year of the sample collection because Barron and Stuerke (1998) report that dating of $\mathrm{I} / \mathrm{B} / \mathrm{E} / \mathrm{S}$ forecasts before the late 1980 s are not reliable. I calculated the mean forecast, the variance of the forecasts, and the number of analysts using the Unadjusted Detail History files to avoid split-adjustment errors caused by rounding (Baber and Kang,

\footnotetext{
${ }^{16}$ I accumulated abnormal returns from day 2 instead of day 1 , because in some cases day 1 is the first day that actual trading is possible after encountering an earnings announcement.
} 
2002; Diether et al., 2002). I calculated analyst forecast errors using actual quarterly and annual earnings from the Unadjusted Detail History Actuals files. ${ }^{17}$ I used the Compustat combined quarterly files to validate earnings announcement dates, and excluded firm-quarters when the $\mathrm{I} / \mathrm{B} / \mathrm{E} / \mathrm{S}$ quarterly earnings announcement date did not match with the Compustat announcement date. I referred to the Center for Research in Security Price (CRSP) to get daily stock prices, daily raw returns, daily size adjusted returns, trading volumes, and the number of shares outstanding.

Table 1 shows the number of firm-quarters used in this study and their distribution over time. The final number of qualified firm-quarters is 23,740 . Panel B of Table 1 shows that the number of observations for the fourth quarter $(2,107)$ is smaller than the number of observations for the first, second, and third quarters. The relatively low number of fourth-quarter observations is caused by requiring at least a sixty-day interval between quarterly earnings announcement dates, and the interval between the fourth-quarter earnings announcement date and the first-quarter earnings announcement date of the next fiscal year is often less than sixty days.

I transformed all independent variables into deciles, based on their sample distributions within calendar quarters - zero represents the smallest decile of each variable and nine represents the largest. I scaled deciles by nine to range between

\footnotetext{
${ }^{17}$ Using unadjusted forecasts and actual earnings is another distinction from Liang (2003) who used adjusted numbers. Since Barron et al.'s (1998) measure of uncertainty is mean 'squared' error of individual forecasts, the uncertainty measured using adjusted numbers and scaled by adjusted stock prices is always lower than the uncertainty measured using unadjusted numbers and scaled by unadjusted stock prices. Therefore, Liang (2003) underestimates information uncertainty for stocks with adjustment factors (i.e., stocks with stock splits and/or stock dividends).
} 
zero and one to make the coefficients easy to be interpreted in the regression results, i.e., the coefficient represents zero investment portfolio returns from short positions in the smallest decile and long positions in the largest decile portfolios (Bernard and Thomas, 1989). I used $99 \%$ winsorization for all the independent variables, i.e., the bottom $0.5 \%$ of the values were set equal to the value corresponding to the 0.5 th percentile, while the upper $0.5 \%$ of the values were set equal to the value corresponding to the 99.5 th percentile. ${ }^{18}$

\footnotetext{
${ }^{18}$ The purpose of using winsorization was to control for outliers when examining descriptive statistics and correlations among variables. The winsorization did not affect regression results because all independent variables were transformed into deciles.
} 


\section{Chapter 5: Empirical Results}

\subsection{Sample Description}

Table 2 shows the descriptive statistics of the sample. The mean of the cumulative abnormal returns from the first through the sixtieth day $\left(C A R \_2 \_60\right)$ after the earnings announcement date is $-0.99 \%$. The mean of the standardized unexpected earnings ( $S U E_{-} A F E$ ) measured using the difference between announced earnings and the mean analyst forecast is -0.00055 , which reflects analysts' forecast optimism. Both the mean $(-0.01105)$ and median $(-0.00074)$ of the change of uncertainty $(\Delta V)$ are negative, which means that information uncertainty decreases over time, i.e., it is lower after the quarterly earnings announcement than before. The mean number of analysts (4.54) and the mean firm size (\$7,874 million) are relatively large because I require that at least two analysts make forecasts both before and after quarterly earnings announcements, and relatively large firms are more likely to meet this condition.

Panel B of Table 2 shows the correlations between main variables. The Spearman correlation coefficients show that cumulative abnormal returns after the earnings announcement $\left(C A R \_2 \_60\right)$ are positively correlated with both $S U E \_A F E$ and SUE_RET, which confirms the general PEAD phenomenon. The negative correlation between cumulative abnormal returns (CAR_2_60) and forecasts dispersion $(D I S P)$ is consistent with prior studies which show that stocks with lower analyst forecast dispersion have higher stock returns (Gebhardt et al., 2001; Diether et 
al., 2002; Dische, 2002). Information uncertainty measured after the quarterly earnings announcement $(V)$ is also negatively associated with $C A R \_2 \_60$. However, the change in information uncertainty $(\Delta V)$, the main variable that I am interested in, shows a significantly positive association with cumulative abnormal returns after the earnings announcement $\left(C A R \_2 \_60\right)$. The change in information uncertainty $(\triangle V)$ is also positively associated with both $S U E_{-} A F E$ and $S U E_{-} R E T$.

Table 3 shows average cumulative return drift after quarterly earnings announcement dates. I rank earnings surprises to make decile portfolios within calendar quarters where the earnings announcement date belongs. CAR_2_60 based on either $S U E \_A F E$ (represented in the third column) or SUE_RET (represented in the fifth column) shows a weaker pattern of PEAD than $C A R \_1 \_60$ based on SUE_AFE deciles (represented in the second column). Overall, the results demonstrated in Table 3 show that larger positive (negative) earnings surprises are associated with larger positive (negative) drift, whichever earnings surprise measure is used for portfolio construction.

\subsection{Test of Hypothesis 1: Sensitivity of Forecast Dispersion to the Market's \\ Response}

I expect that analysts incorporate the market's response surrounding earnings announcements when updating their earnings forecasts, and I also expect that this behavior is conspicuous when there are large earnings surprises. Specifically, the 
first hypothesis is that when large earnings surprises occur, analyst forecast dispersion is lower for firms with confirming abnormal returns surrounding the earnings announcement than for firms without confirming abnormal returns.

Table 4 summarizes the pattern of analyst forecast dispersion across earnings surprise ranks. ${ }^{19}$ First, Panel A of Table 4 shows the general distributions of analyst forecast dispersion $(D I S P)$ - which are measured using annual earnings forecasts made after earnings announcements - and change of information uncertainty $(\Delta \mathrm{V})$ across $S U E \_A F E$ deciles (the left half of the columns) and SUE_RET deciles (the right half of the columns), respectively. The lowest and the highest $S U E \_A F E$ deciles have greater forecast dispersion than mid-range $S U E_{-} A F E$ deciles; forecast dispersion of the lowest (highest) $S U E \_A F E$ is 0.0047 (0.0041). The lowest and the highest $S U E \_A F E$ deciles consequently have more change of information uncertainty $(\triangle V)$ than mid-range $S U E \_A F E$ deciles; change of information uncertainty of the lowest (highest) $S U E \_A F E$ is $-0.0453(-0.0221)$. However, the right half of the columns in Panel A show that this pattern is much weaker when $S U E_{-} R E T$ deciles are used, although the lowest and the highest deciles have relatively large forecast dispersion and change of information uncertainty compared to mid-range $S U E \_R E T$ deciles. In sum, the results of Panel A imply that the distribution of analyst forecast

\footnotetext{
${ }^{19}$ Note that unlike the final sample used for sample descriptions and the final regression analysis, the forecasts used in Table 4 include forecasts updated early after earnings announcements, i.e., forecast window $(0,45)$ instead of $(6,45)$, where 0 is the earnings announcement date. In the first and second hypotheses' tests, I describe the problem of including early updated forecasts.
} 
dispersion is quite different between $S U E \_A F E$ and $S U E \_R E T$, although both measures are regarded as interchangeable standardized unexpected earnings measures.

Panel B of Table 4 shows test results of $H 1$. It shows that when forecast errors are held constant, analyst forecast dispersion changes according to the market's responses to the forecast errors. The twenty-five portfolios of analyst forecast dispersion are constructed by using a combination of $S U E \_A F E$ quintiles and SUE_RET quintiles. The second to last row (labeled SUE_AFE Quintile 5) shows that when there are large positive forecast errors, analyst forecast dispersion decreases monotonically as the market's response becomes more positive (from 0.0047 to 0.0026 ). Analyst forecasts dispersion is greatest when the two earnings surprise measures reach the highest level of disagreement. Dispersion is 0.0047 for observations in $S U E \_A F E$ Quintile 5 and $S U E \_R E T$ Quintile 1 - row 5 column 1 of Panel B. Similarly, in row 1 column 5, dispersion is 0.0046 . Note that when there are large positive forecast errors, the market is likely to show large positive returns. Consequently, the number of observations increases from 935 (at $S U E \_A F E 5$ and SUE_RET 1) to 2,507 (at SUE_AFE 5 and SUE_RET 5). The average return drift of the portfolio formed by $S U E \_A F E 5$ and $S U E \_R E T 5$ is greater than the average return drift of the portfolio formed by SUE_AFE 5 and $S U E_{-} R E T 1{ }^{20}{ }^{20}$ Therefore, a regression of the return drift on analyst forecast dispersion is likely to show a

\footnotetext{
${ }^{20}$ Untabulated results show that the portfolio formed by SUE_AFE 5 and SUE_RET 5 has $9.87 \%$ cumulative abnormal return over the next 60 days after earnings announcements, while the portfolio formed by $S U E_{-} A F E 5$ and $S U E_{-} R E T 1$ has $-5.87 \%$ cumulative abnormal returns on average.
} 
negative association between them. However, as shown in Panel B of Table 4, the small forecast dispersion could be a mere reflection of analysts following of the market's response to earnings news. In sum, these results imply that analyst forecast dispersion may not be a good proxy for information uncertainty.

I argue that a better measure of information uncertainty (or a measure which is less influenced by the market's response) is to use analysts' forecasts updated late after the earnings announcement. The next section considers whether the use of late updated forecasts lessen the problem of the sensitivity of forecast dispersion to the market's response.

\subsection{Test of Hypothesis 2: Difference of Forecast Dispersions between Forecast Window $(0,5)$ and Forecast Window $(6,45)$}

The second hypothesis is about whether forecast dispersion varies depending on the timing of forecasts. I hypothesize that the dispersion of early updated forecasts after an earnings announcement is lower than the dispersion of late updated forecasts after the announcement. This hypothesis is directly related to the research method chosen to investigate $H 3$, and the test results show why the late updated forecasts are appropriate forecasts to measure information uncertainty.

Before testing the second hypothesis, I first examine analysts' forecast updating pattern in general, and Table 5 summarizes the results. First of all, note that the number of observations in this examination is different from the final firm-quarter 
observations, because this test examines the updating behavior of all the analysts. The sample includes 397,432 analysts who made one-year-ahead annual earnings forecasts within forty-five days before the quarterly earnings announcement date (two-year-ahead annual earnings forecast before the fourth-quarter earnings announcement date). The table reports how soon (Panel A) and how often (Panel B) analysts update their annual earnings forecasts within forty-five days after the quarterly earnings announcement. ${ }^{21}$

Panel A of Table 5 shows how soon analysts update their forecasts. About $5 \%$ of the analysts update their forecasts on the same day as the quarterly earnings announcement, and the next day is the most congested with forecast updates; about $28 \%$ of the updates are concentrated on this single day. More than half of the updates have been made by the end of the third day after the earnings announcement, and the number of updates made on each day decreases drastically afterwards. Only one or two percent of the updates are made each day near the end of the forty-five day post announcement period.

Panel B of Table 5 shows how many times analysts update earnings forecasts within forty-five days after the quarterly earnings announcement date. The majority of forecasts (65\%) are updated only once during this period, about $26 \%$ of the forecasts updated twice, and less than ten percent of the forecasts are updated more than twice. In sum, Table 5 confirms that analysts care about the timeliness of their

\footnotetext{
${ }^{21}$ Strictly speaking, 397,432 sample observations are not the number of analysts but the number of analyst-firm-quarters.
} 
forecast updates, and the majority of the forecasts are updated within three days after earnings announcements, which are used in Liang's (2003) measure of information uncertainty.

I examine, as a next step, whether there is a difference in the dispersion and the change of information uncertainty between the early updated forecasts and the late updated forecasts. Panel A of Table 6 shows the results of the comparison between the two groups of forecasts: one group is based on the forecasts made within five days after the earnings announcement $\left(D I S P \_0 \_5\right.$, and $\left.\Delta V \_0 \_5\right)$ and the other group is based on the forecasts made between the sixth day and the forty-fifth day after the announcement (DISP_6_45, and $\left.\Delta V \_6 \_45\right)$. The last row shows that on average the dispersion of the late updated forecasts (0.0043) is significantly larger than the dispersion of the early updated forecasts $(0.0015)$ at the level of 0.01 , and that there is more change in information uncertainty (i.e., larger absolute values) in late updated forecasts $(-0.0115)$ than in early updated forecasts $(-0.009)$.

Among SUE_AFE deciles, five deciles, including the lowest and the highest deciles, have significantly greater forecast dispersion for late forecasts relative to early forecasts. As for change of information uncertainty, the difference between the two groups is significantly large when forecast errors are positive (SUE_AFE 6 through SUE_AFE 9).

One may argue that the different levels of dispersion $(D)$ do not necessarily result in different levels of information uncertainty $(V)$ because information 
uncertainty is also dependent on the squared error of the mean forecast $(S E)$. Note that $V=\left(1-\frac{1}{N}\right) D+S E$. If $S E$ moves to the opposite direction of the change of dispersion and compromises the influence of $D$ on $V$, there would be no change in information uncertainty resulting from the change of dispersion. Therefore, in order to determine whether the different levels of dispersion between early updated and late updated forecast groups result in different information uncertainty $(V)$, I examine information uncertainty $(V)$ and squared error of the mean forecast $(S E)$ of the early updated and the late updated forecast groups separately. Panel B of Table 6 shows the results. The last row shows that the late updated forecast group has significantly greater information uncertainty $(0.0613)$ than the early updated forecast group (0.0274). The differences of the information uncertainty between the two groups are concentrated in the extreme deciles of the standardized unexpected earnings (SUE_AFE 1 and $S U E \_A F E$ 10). However, there is no significant difference in the squared error of the mean forecast between the early updated and the late updated forecast groups. The last row shows that $S E$ of the early (late) updated forecast group is $0.0563(0.0582)$, and that the difference in $S E$ is not significant. In sum, I conclude that there is a significant difference in information uncertainty between early updated and late updated forecast groups, and this is caused by differences in the analyst forecast dispersion between the two groups.

Panel C and D of Table 6 show the difference of the sensitivity of the change of information uncertainty to the market's response (i.e., $S U E_{-} R E T$ ) between early 
updated forecasts group (Panel C of Table 6) and late updated forecasts group (Panel $\mathrm{D}$ of Table 6). Panel $\mathrm{C}$ shows that in four of the five rows, the difference of change of uncertainty between $S U E_{-} R E T 1$ and $S U E_{-} R E T 5$ is greater than the difference in the corresponding row of Panel D. In Panel D, except for $S U E \_A F E$ Quintile 4 row, there is no significant difference of change of uncertainty between SUE_RET 1 and SUE_RET 5. These results indicate that change of information uncertainty is more influenced by the market's response for early updated forecasts group than for late updated forecasts group. ${ }^{22}$

Figure 5 shows the changing pattern of the mean analyst forecast dispersion (Panel A) and mean change of uncertainty (Panel B) over one year forecast horizons when forecasts are grouped using forecast window $(0,5)$ and $(6,45)$ alternately. Forecast dispersion decreases as forecast horizon becomes short. However, it does not decrease monotonically. Dispersion of the late updated forecasts (i.e., forecast window $(6,45))$ is larger than the dispersion of the early updated forecasts (i.e., forecast window $(0,5))$, although late updated forecasts have shorter forecast horizons than early updated forecasts. Similarly, Panel B shows that absolute value of change of uncertainty decreases (i.e., less change of uncertainty) as forecast horizon becomes short. However, there is more change of uncertainty (i.e., larger absolute value of change of uncertainty) of forecast window $(6,45)$ than for the case

\footnotetext{
${ }^{22}$ Similarly, untabulated test results also show that the dispersion of the early updates are much more sensitive to the market's response than the dispersion of the late updates.
} 
of forecast window $(0,5)$, although late updated forecasts have shorter forecast horizon than early updated forecasts.

In summary, the results of Table 6 and Figure 5 support my second hypothesis, and I conclude that the dispersion of the late updated forecasts is larger than the dispersion of the early updated forecasts. Moreover, the results indicate that when using forecasts updated late, analysts' forecasts are not as sensitive to the market's response as in the case of early updated forecasts. Therefore, I infer that information uncertainty can be measured more accurately with the use of late updated forecasts.

\subsection{Test of Hypothesis 3: Regression Result}

Finally, I examine whether the change of information uncertainty $(\Delta V)$ has a positive incremental effect on PEAD. Table 7 reports results of various regressions that examine whether forecast collection timing makes a difference in the incremental effects of change of information uncertainty on PEAD. Panel A and Panel B of Table 7 use the forecast window $(0,5)$, which represents early updated forecasts. Panel A reports the regression results when independent variables are limited to the change of information uncertainty $(\Delta V)$ and the earnings surprise measure. Panel B shows the regression results when control variables are added. Panel C and Panel D of Table 7 report results for forecast window $(6,45)$, which represents late updated forecasts.

I control for firm size, which is known to decrease the influence of the earnings surprise on returns (Atiase, 1985; Freeman, 1987). To calculate firm size 
(SIZE), I multiply the closing stock price on the 45th day before the earnings announcement date with the number of shares outstanding on the same date. I control for the number of analysts $(A N U M)$, which is demonstrated to represent the incremental information flow around the earnings announcement (Bartov et al., 2000). Since earnings momentum and price momentum are closely related (Chan et al., 1996; Chordia and Shivakumar, 2006), I control for price momentum by including compound return $(C O M P)$ over the six months prior to the earnings announcement. I also control for trading volume $(V O L)$, which is shown to increase price momentum (Lee and Swaminathan, 2000). Trading volume is measured as the average daily turnover during the forty-five days before the earnings announcement, where daily turnover is the ratio of the number of shares traded each day to the number of shares outstanding. Finally, I examine whether there is a difference between positive earnings surprise and negative earnings surprise. If the earnings surprise is positive, the dummy variable $(S I G N)$ is 1 , and it is 0 otherwise.

Panel A of Table 7 shows that the coefficient estimate $(0.0411)$ of the unexpected earnings variable $\left(S U E_{-} A F E\right)$ is positive and significant. The parameter estimate of $\triangle V \times S U E \_A F E$ is -0.0398 and significant at the 0.01 level. This implies that the return to a zero-investment portfolio, consisting of firms in the lowest information uncertainty $(\triangle V)$ with a long position in $S U E \_A F E$ decile 10 and a short position in SUE_AFE decile 1, is $4.11 \%$. The incremental change in the above return is $-3.98 \%$ if positions are taken in the highest as opposed to the lowest $\Delta V$ decile; this 
means that the change of information uncertainty and PEAD is negatively associated, but note that early updated forecasts are used in regressions of Panel A and Panel B.

Panel B of Table 7 shows the result of the multiple regression including control variables. The parameter estimate of $\triangle V \times S U E \_A F E$ is still negative $(-0.0399)$ and significant at the 0.01 level, while the parameter estimates of $C O M P \times S U E \_A F E$ and $A N U M \times S U E \_A F E$ are 0.0474 and 0.0233 , respectively. The estimates of both the compounded return $\left(C O M P \times S U E_{-} A F E\right)$ and the number of analysts $\left(A N U M \times S U E \_A F E\right)$ are significant at the 0.01 level. This result implies that the incremental change in return is $4.74 \%$ and $2.33 \%$ if positions are taken in the highest as opposed to the lowest $C O M P$ and $A N U M$ deciles, respectively.

The negative coefficients of change of information uncertainty $\left(\triangle V \times S U E \_A F E\right)$ shown in Panel A and Panel B are consistent with Liang's (2003) results. As I discussed earlier, I ascribe these results to the usage of early forecast updates, and I expect that the change of uncertainty $(\triangle V)$ and return drift $\left(C A R \_2 \_60\right)$ will be positively associated when using late forecast updates.

The regression results in Panel C and D of Table 7, which are based on late updated forecasts $(6,45)$, meet my expectation. Both regression results show that the change of information uncertainty $(\Delta V)$ has a positive incremental effect on return drift. Panel D of Table 7 shows the result of the complete regression model. The coefficient estimate of the unexpected earnings variable $\left(S U E \_A F E\right)$ is 0.0012 . The parameter estimates of $\triangle V \times S U E \_A F E$, SIZE $\times S U E \_A F E, V O L \times S U E \_R E T$, 
$C O M P \times S U E \_R E T$, and $A N U M \times S U E \_R E T$ are $0.0239,0.0182,0.0176,0.0398$ and -0.0296 , respectively, and all are significant at the 0.05 level. This implies that the return to a zero-investment portfolio, consisting of firms in the lowest information uncertainty $(\triangle V)$, the lowest firm size $(S I Z E)$, the lowest trading volume $(V O L)$, the lowest compound return (COMP), and the lowest number of analysts (ANUM) with a long position in $S U E \_A F E$ decile 10 and a short position in $S U E \_A F E$ decile 1, is $0.12 \%$. The incremental change in the above return is $2.39 \%, 1.82 \%, 1.76 \%, 3.98 \%$ and $-2.96 \%$ if positions are taken in the highest as opposed to the lowest $\triangle V, S I Z E$, $V O L, C O M P$, and $A N U M$ deciles. The only coefficient estimate that does not meet my expectation is firm size (SIZE), which shows positive incremental effect on return drift. I speculate that this is caused by the fact that the sample contains mostly large firms, and it is difficult to discriminate a firm size effect in a sample comprised of only relatively large firms.

In summary, through the regression results shown in Table 7, I conclude that the effect of the change of information uncertainty on return drift is sensitive to the collection timing of analysts' forecasts. When an appropriate collection timing of analysts' forecasts is used (i.e., forecast window $(6,45))$, information uncertainty that is extracted from analysts' forecasts is positively (not negatively) associated with PEAD. 


\section{Chapter 6: Supplemental Tests}

\subsection{Forecast Error Based $S U E$ versus Abnormal Return Based $S U E$}

I supplement the tests in Table 7 with regressions using abnormal returns surrounding earnings announcements as an alternative earnings surprise measure ( $S U E \_R E T$ ), because tests of $H 1$ find that analyst forecast dispersion is sensitive to the market's response to earnings surprises. If $S U E_{-} R E T$ is a better earnings surprise measure to control for the sensitivity of analyst forecast dispersion, I expect that it will support the positive association between information uncertainty and PEAD more strongly than $S U E \_A F E$.

Table 8 shows the regression results when $S U E_{-} R E T$ is used as an earnings surprise measure. The regressions are based on the late updated forecasts (forecasts window of $(6,45)){ }^{23}$ Since $S U E \_R E T$ is the three day cumulative abnormal returns surrounding earnings announcement dates, the dependent variable of the regression is defined as cumulative abnormal returns between the second and the sixtieth day after earnings announcement dates $\left(C A R \_2 \_60\right)$ instead of $C A R \_1 \_60$.

The results show that the change of information uncertainty has a positive incremental effect on return drift in both regressions. Moreover, the coefficient estimates of $\Delta V(0.0539$ in Panel $\mathrm{A}$ and 0.0429 in Panel $\mathrm{B}$ of Table 8$)$ are larger than

\footnotetext{
${ }^{23}$ To make the table succinct, I did not present the regression result of using forecasts window $(0,5)$. The regression result of forecast window $(0,5)$ shows that change of information uncertainty and return drift are negatively associated. In sum, regardless of the earnings surprise measures, change of information uncertainty has a negative incremental effect on return drift when early forecast updates are used.
} 
the corresponding estimates shown in Table 7 (0.0361 in Panel C and 0.0294 in Panel D). This result supports the idea that when $S U E_{-} R E T$ is used as the earnings surprise measure, the positive association between information uncertainty and PEAD is more strongly supported than when earnings surprises are measured with $S U E \_A F E$.

\subsection{Change in Information Uncertainty versus Level of Information}

\section{Uncertainty}

I also ran regressions using the level of information uncertainty $(V)$ instead of the change of information uncertainty $(\Delta V)$, and the results are reported in Table $9 .^{24}$ The results show that the level of uncertainty also has a positive incremental effect on return drift in both regressions, but the coefficient estimates of $V(0.0093$ in Panel A) is significant only at the level of 0.10 . Overall, the coefficient estimates of $V(0.0093$ in Panel A and 0.0149 in Panel B of Table 9) are much smaller than the corresponding estimates shown in Table 8 (0.0539 in Panel A and 0.0429 in Panel B). Untabulated test results show that when $S U E \_A F E$ is used as an earnings surprise measure, the level of information uncertainty $(V)$ no longer has a positive incremental effect on PEAD. In summary, I conclude that change of information uncertainty shows a stronger positive association with PEAD than does level of uncertainty.

\footnotetext{
${ }^{24}$ The number of firm-quarters increased to 49,594 for this regression because analysts do not have to make forecasts before earnings announcement dates, which is required to measure change of uncertainty. Using the original sample $(\mathrm{N}=23,740)$, however, provides the same result as using the increased number of firm-quarters.
} 


\subsection{Sub-sample Tests}

Finally, I ran regressions using sub-samples to see if my results are consistent across different quarters and different years. For the tests shown in Table 10, I use SUE_RET as the earnings surprise measure, and I also use late forecast updates. Panel A of Table 10 shows the regression results of four different quarters. Except for the third quarter, in which the coefficient estimate of the change of uncertainty is negative but insignificant $(-0.0062)$, the first, the second, and the fourth quarters have positive and significant coefficient estimates of the change of uncertainty. I speculate that coefficient in the third quarter is not significantly positive because the third quarter sub-sample has the shortest forecast horizon. ${ }^{25}$ As the forecast horizon becomes short, forecast errors and consequently change of uncertainty become smaller (see Figure 5). The comparison of the mean forecast errors between quarterly sub-samples, which is not tabulated, confirms that the third-quarter sub-sample has the smallest forecast error and the smallest change of uncertainty. Therefore, I conclude that in the third-quarter sub-sample, the change of uncertainty might be not large enough to show a positive association with the return drift.

Panel B of Table 10 shows the regression results of six different two- and three-year sub-samples. Among those six, three sub-samples show positive and significant coefficient estimates of the change of uncertainty, while the other three

\footnotetext{
${ }^{25}$ Note that I use one-year-ahead annual earnings forecasts for the first, second, and the third firmquarters, while using two-year-ahead (one-year-ahead) annual earnings forecasts before (after) the fourth-quarter earnings announcement. Therefore, the third quarter has the shorted forecast horizon.
} 
groups show insignificant coefficient estimates. When I examine the coefficient estimates of the change of uncertainty year by year, which is not tabulated, only five annual samples have negative coefficients, while twelve annual samples have positive coefficients among the total seventeen annual samples; only one year (2003) shows a significantly negative coefficient, while seven annual samples show significantly positive coefficients at the 0.01 level. Therefore, I conclude that the positive association between change of information uncertainty and return drift is valid over the years in general. ${ }^{26}$

I notice that especially recent samples (2001-2005) do not support my hypothesis very well, and I wonder if the adoption of Regulation Fair Disclosure (Reg FD) is associated with this result. There is a stream of studies which examine the influence of Reg FD on analysts' forecasts. Although an earlier study of Heflin, Subramanyam, and Zhang (2003) argues that there is no reliable evidence of changes in analysts' earnings forecast errors or dispersion, more recent studies using larger samples find that analysts' forecast accuracy decreased and forecast dispersion increased after Reg FD was adopted (Bailey, Li, Mao, and Zhong, 2003; Agrawal, Chadha, and Chen, 2006). Examining my samples, I have the same results as shown in Bailey et al. (2003) and Agrawal et al. (2006). Since analyst forecast accuracy and dispersion are main variables to measure information uncertainty in this study, Reg

\footnotetext{
${ }^{26}$ Because of the variance of the coefficients over time, I ran Fama-MacBeth type regressions. The results are shown in Table 11. The coefficients for the change of uncertainty is still positive $(0.0410)$ and significant.
} 
FD may influence the result of this study by changing forecast accuracy and dispersion.

An alternative explanation is that the Reg FD might influence PEAD directly by changing the information flow of the market and speed of the price lead on earnings as posited by Ayers and Freeman (2003). My coarse examination, which is not tabulated, shows that arbitrage profits obtained from zero-investment portfolios are smaller in the post-Reg FD period than in the pre-Reg FD period. In summary, I speculate that Reg FD might weaken my conclusion about the positive relation between the information uncertainty extracted from analysts' forecasts and return drift, and that could be an interesting future research topic. 


\section{Chapter 7: Summary and Conclusions}

This dissertation examines the association between information uncertainty measured using analysts' forecasts and PEAD. Several prior studies posit and find that information uncertainty measured through analyst forecast dispersion is negatively associated with PEAD. This result is contradictory to the prediction based on traditional PEAD studies. Moreover, studies that use various other proxies for information uncertainty besides analyst forecast dispersion find a positive association between information uncertainty and PEAD. This study attempts to reconcile these conflicting empirical results. In this study, I show that information uncertainty is in fact positively associated with PEAD, even when analysts' forecasts are used to measure information uncertainty.

I find that the negative association of prior studies is caused by not fully considering analyst forecast behavior after earnings announcements. Information uncertainty measured using analysts' forecasts is sensitive to forecast collection timing (i.e., when the forecasts are made). I argue that late updated forecasts are more appropriate than early updated forecasts to measure information uncertainty because early updated forecasts are heavily influenced by public information such as the market's response to earnings surprises. In contrast, late updated forecasts are the result of incorporating both public and private information, which provides a broader view into investors' actual information environment. 
I also argue that early updated forecasts are inappropriate to measure information uncertainty because analysts' concern of the timeliness of their forecasts causes them to make hasty forecasts, which contaminate not only forecast accuracy but also forecast dispersion of the early updated forecasts. I find that early updated forecasts have lower forecast dispersion than late updated forecasts. By using late updated forecasts, I find that information uncertainty is in fact positively (not negatively) associated with PEAD.

My research contributes to the accounting literature by clarifying the association among analyst forecast dispersion, information uncertainty, and PEAD. Most importantly, by showing the positive association between information uncertainty and PEAD, this study strengthens the argument that reducing information uncertainty improves market efficiency, i.e., more reliable or more objective information is beneficial to the market. This study also contributes to the literature about analysts' forecasts by showing that analysts' forecasts need to be carefully collected and modified to properly represent information uncertainty. Finally, this study adds insight on why PEAD exists. By showing the positive relation between information uncertainty and PEAD, this study provides empirical support for the argument of Daniel et al. (1998), which attributes PEAD to overconfidence in private information and self-attribution bias, although it does not rule out other PEAD explanations. 


\section{Table 1. Sample Selection}

Panel A. Number of firm-quarters

\begin{tabular}{|c|c|}
\hline 53,436 & $\begin{array}{l}\text { All firm-quarters having more than one analyst who make forecasts both before } \\
\text { and after quarterly earnings announcements. }\end{array}$ \\
\hline 46,480 & Firm-quarters having necessary Compustat and CRSP data. \\
\hline 31,909 & $\begin{array}{l}\text { Firm-quarters having the same quarterly earnings announcement date in } \mathrm{I} / \mathrm{B} / \mathrm{E} / \mathrm{S} \\
\text { and Compustat. }\end{array}$ \\
\hline 29,506 & $\begin{array}{l}\text { Firm-quarters having greater than or equal to } \$ 1.00 \text { closing stock price on the } \\
\text { forty-fifth day before the quarterly earnings announcement date. }\end{array}$ \\
\hline 23,740 & $\begin{array}{l}\text { Firm-quarters having greater than } 60 \text { days and less than } 90 \text { days interval before } \\
\text { the next quarter's announcement date. }\end{array}$ \\
\hline
\end{tabular}

Panel B. Sample distribution by fiscal years and by fiscal quarters

\begin{tabular}{cc} 
Year & Firm-quarters \\
\hline 1989 & 916 \\
1990 & 1190 \\
1991 & 1126 \\
1992 & 1109 \\
1993 & 950 \\
1994 & 1434 \\
1995 & 1312 \\
1996 & 1484 \\
1997 & 1622 \\
1998 & 1925 \\
1999 & 1621 \\
2000 & 1203 \\
2001 & 1570 \\
2002 & 1519 \\
2003 & 1606 \\
2004 & 1647 \\
2005 & 1506 \\
Total & 23,740 \\
\hline Quarter & Firm-quarters \\
\hline 1 & 7528 \\
2 & 6795 \\
3 & 7310 \\
4 & 2107 \\
Total & 23,740 \\
\hline
\end{tabular}

\footnotetext{
${ }^{\dagger}$ Analysts' forecasts are one-year-ahead annual earnings forecasts. Two-year-ahead annual earnings forecasts are used only before the fourth-quarter earnings announcement, and one-year-ahead annual earnings forecasts are used after the fourth-quarter earnings announcement to match the same annual earnings forecasts. To be included in the sample, at least two analysts must make annual earnings forecast within forty-five days before the quarterly earnings announcement date and they must update their annual earnings forecast between the sixth day and the forty-fifth day after the quarterly earnings announcement date, i.e., the forecast windows are $(-45,-1)$ and $(6,45)$, where 0 is the quarterly earnings announcement date.
} 
Table 2. Sample Description

Panel A: Descriptive statistics $(N=23,740)$

\begin{tabular}{lccc}
\hline Variables & Mean & Std. Error & Median \\
\hline Cumulative Abnormal Returns $\left(C A R \_2 \_60\right)$ & -0.00993 & 0.21087 & -0.01329 \\
Standardized Unexpected Earnings $\left(S U E \_A F E\right)$ & -0.00055 & 0.03599 & 0.00025 \\
SUE measured by three day abnormal returns & 0.00167 & 0.07513 & 0.00092 \\
$\left(S U E \_R E T\right)$ & 0.00431 & 0.08915 & 0.00012 \\
Forecasts Dispersion $(D I S P)$ & 0.59057 & 0.48422 & 0.81684 \\
Correlation of the Forecast Errors $(\rho)$ & 0.05698 & 1.59840 & 0.00103 \\
Uncertainty $(V)$ & -0.01105 & 0.04904 & -0.00074 \\
Change of Uncertainty $\left(\triangle V: V \_a f t e r-V \_b e f o r e\right)$ & 0.05384 & 1.59337 & 0.00065 \\
Squared Error of the Mean Forecast $(S E)$ & 4.54 & 3.57 & 3.0 \\
Number of Analysts Following $(N)$ & 7873.6 & 24191.2 & 1588.4 \\
Firm Size (SIZE, millions) & & & \\
\hline
\end{tabular}


Table 2. Continued

Panel B: Spearman Correlation Coefficients $(N=23,740)$

\begin{tabular}{|c|c|c|c|c|c|c|c|c|}
\hline & ${ }_{6 \overline{0}}^{C A R}{ }^{2}-$ & $S U E_{-} A F E$ & $S U E_{-} R E T$ & DISP & $\rho$ & $\boldsymbol{V}$ & $\Delta V$ & SIZE \\
\hline \multicolumn{9}{|l|}{$C A R \_2 \_60$} \\
\hline$S U E \_A F E$ & $0.0765^{* *}$ & & & & & & & \\
\hline$S U E \_R E T$ & $0.0593 * *$ & $0.2648 * *$ & & & & & & \\
\hline DISP & $-0.0205^{* *}$ & $0.0141^{*}$ & $-0.0373 * *$ & & & & & \\
\hline$\rho$ & -0.0119 & -0.0081 & 0.0094 & $-0.3827 * *$ & & & & \\
\hline $\boldsymbol{V}$ & $-0.0250 * *$ & 0.0103 & $-0.0242 * *$ & $0.6171 * *$ & $0.3725^{* *}$ & & & \\
\hline$\Delta V$ & $0.0878 * *$ & $0.1216^{* *}$ & $0.0691 * *$ & $-0.2677 * *$ & $-0.0214 * *$ & $-0.2703 * *$ & & \\
\hline$S I Z E$ & $0.0562 * *$ & 0.0104 & $0.0180 * *$ & $-0.0745 * *$ & $-0.0853 * *$ & $-0.1542 * *$ & $0.1253 * *$ & \\
\hline
\end{tabular}

Spearman (Pearson) correlation coefficients are shown in the top (bottom) triangle.

* Significant at $p<0.05$.

** Significant at $p<0.01$.

$C A R \_2 \_60$ is cumulative size-adjusted return over the trading day window $(2,60)$, where 2 is the second day after the earnings announcement date. The daily abnormal return for firm $j$ on day $t\left(A R_{j t}\right)$ is computed as follows: $A R_{j t}=R_{j t}-R_{p t}$, where $R_{j t}$ is the daily raw return for firm $j$ on day $t$ and $R_{p t}$ is the equally weighted mean return on day $t$ of the NYSE/AMEX/NASDAQ firm size decile.

$S U E \_A F E=($ IBES Actual quarterly EPS - Mean Forecast) / Stock_Price_45Days, where Mean Forecast is the average of the one-quarter-ahead forecasts made within forty-five days before the earnings announcement date, and Stock Price 45Days is the closing stock price on the 45th day before the earnings announcement date. The firm-quarters must have at least two analysts' forecasts, and Stock_Price_45Days must be greater than or equal to $\$ 1.00$ to be included in the sample.

$S U E \_R E T$ is cumulative size-adjusted return over the trading day window $(-1,1)$ surrounding the earnings announcement date. The daily abnormal return is calculated in the same manner as explained in CAR_2_60 variable. 
$D I S P=\frac{1}{N-1} \sum_{i=1}^{N} E\left(f_{i}-f\right)^{2}$, where $f_{i}$ is the earnings forecast by analyst $i, f$ is the mean forecast across analysts, and $N$ is the number of forecasts.

$S E=(y-f)^{2}$, where $y$ is the actual earnings per share and $f$ is the mean forecast.

$\rho=\frac{S E-D I S P / N}{(1-1 / N) D I S P+S E}$

$V=\left(1-\frac{1}{N}\right) D I S P+S E$

SIZE is the multiplication of the number of shares outstanding on the 45th day before the earnings announcement date and the closing stock price of the same date.

Note:

1. Analysts' forecasts used for each variable are one-year-ahead annual earnings forecasts. Two-yearahead annual earnings forecast are used for the variable calculation before the fourth quarter earnings announcement only, and one-year-ahead annual earnings forecasts are used after the fourth-quarter earnings announcement to match the same annual earnings forecasts

2. DISP, $S E, V$ are scaled by the closing stock price on the 45 th day before earnings announcement date.

3. Except for CAR_2_60, all variables are deciles transformations based on their sample distribution within calendar quarters where the earnings announcement date belongs.

4. If there is no additional indication such as '_before', all variables are calculated using analysts' forecasts made after the quarterly earnings announcement. 
Table 3. Return Drift

\begin{tabular}{lcc||lc}
\hline $\begin{array}{c}\text { SUE_AFE } \\
\text { Decile }\end{array}$ & CAR_1_60 & CAR_2_60 & $\begin{array}{c}\text { SUE_RET } \\
\text { Decile }\end{array}$ & CAR_2_60 \\
\hline 1 (Lowest) & -0.031 & -0.017 & 1 (Lowest) & -0.038 \\
2 & -0.029 & -0.022 & 2 & -0.021 \\
3 & -0.032 & -0.025 & 3 & -0.018 \\
4 & -0.032 & -0.029 & 4 & -0.007 \\
5 & -0.025 & -0.022 & 5 & -0.015 \\
6 & -0.015 & -0.017 & 6 & -0.009 \\
7 & 0.004 & -0.002 & 7 & 0.003 \\
8 & 0.003 & -0.004 & 8 & -0.006 \\
9 & 0.019 & 0.010 & 9 & -0.005 \\
10 (Highest) & 0.039 & 0.028 & 10 (Highest) & 0.018 \\
\hline $10-1$ & 0.070 & 0.045 & $10-1$ & 0.056 \\
\hline
\end{tabular}

Deciles are formed based on rankings of standardized unexpected earnings within calendar quarters.

CAR_1(2)_60 is cumulative size-adjusted return over the trading day window of (1(2), 60), where 1 (2) is the first (second) day after the earnings announcement date. The daily abnormal return for firm

$j$ on day $t\left(A R_{j t}\right)$ is computed as follows: $A R_{j t}=R_{j t}-R_{p t}$, where $R_{j t}$ is the daily raw return for firm $j$ on day $t$ and $R_{p t}$ is the equally weighted mean return on day $t$ of the NYSE/AMEX/NASDAQ firm size decile.

SUE_AFE $=($ IBES Actual quarterly EPS - Mean Forecast $) /$ Stock_Price_45Days, where Mean $\bar{F}$ orecast is the average of the one-quarter-ahead forecasts made within forty five days before the earnings announcement date, and Stock_Price_45Days is the closing stock price on the 45th day before the earnings announcement date. The firm-quarters must have at least two analysts' forecasts, and Stock_Price_45Days must be greater than or equal to $\$ 1.00$ to be included in the sample.

$S U E \_R E T$ is cumulative size-adjusted return over the trading day window $(-1,1)$ surrounding the earnings announcement date. The daily abnormal return is calculated in the same manner as explained in CAR_1_60 variable. 
Table 4. Analyst Forecast Dispersion and Change of Information Uncertainty Panel A. DISP (Analyst forecast dispersion) and $\triangle V$ (Change of information uncertainty) distribution by earnings surprise deciles $(\mathrm{N}=38,679)$

\begin{tabular}{ccc|ccc}
\hline $\begin{array}{c}\boldsymbol{S U E} \text { _AFE } \\
\text { Decile }\end{array}$ & $\boldsymbol{D I S P}$ & $\boldsymbol{\Delta V}$ & $\begin{array}{c}\boldsymbol{S U E} \text { RET } \\
\text { Decile }\end{array}$ & $\boldsymbol{D I S P}$ & $\boldsymbol{\Delta} \boldsymbol{V}$ \\
\hline 1 (Lowest) & 0.0047 & -0.0453 & 1 (Lowest) & 0.0023 & -0.0218 \\
2 & 0.0015 & -0.0107 & 2 & 0.0018 & -0.0143 \\
3 & 0.0008 & -0.0057 & 3 & 0.0015 & -0.0105 \\
4 & 0.0007 & -0.0048 & 4 & 0.0014 & -0.0088 \\
5 & 0.0006 & -0.0031 & 5 & 0.0016 & -0.0097 \\
6 & 0.0007 & -0.0034 & 6 & 0.0015 & -0.0089 \\
7 & 0.0008 & -0.0037 & 7 & 0.0015 & -0.0088 \\
8 & 0.0011 & -0.0044 & 8 & 0.0014 & -0.0077 \\
9 & 0.0015 & -0.0065 & 9 & 0.0015 & -0.0084 \\
10 (Highest) & 0.0041 & -0.0221 & 10 (Highest) & 0.0018 & -0.0108 \\
\hline Mean & 0.0016 & -0.0109 & Mean & 0.0016 & -0.0109 \\
\hline
\end{tabular}

Panel B. DISP (Analyst forecast dispersion) by earnings surprise quintiles

\begin{tabular}{|c|c|c|c|c|c|c|c|}
\hline \multicolumn{8}{|c|}{$S U E_{-} R E T$ Quintile } \\
\hline & & 1 & 2 & 3 & 4 & 5 & $5-1$ \\
\hline \multirow{6}{*}{$\begin{array}{l}S U E_{-} \\
A F E \\
\text { Quintile }\end{array}$} & 1 & $\begin{array}{c}0.0039 \\
(\mathrm{~N}=2592)\end{array}$ & $\begin{array}{c}0.0025 \\
(\mathrm{~N}=1762)\end{array}$ & $\begin{array}{c}0.0032 \\
(\mathrm{~N}=1360)\end{array}$ & $\begin{array}{c}0.0035 \\
(\mathrm{~N}=1042)\end{array}$ & $\begin{array}{l}\mathbf{0 . 0 0 4 6} \\
(\mathrm{N}=872)\end{array}$ & 0.0008 \\
\hline & 2 & $\begin{array}{c}0.0007 \\
(\mathrm{~N}=1790)\end{array}$ & $\begin{array}{c}0.0010 \\
(\mathrm{~N}=1870)\end{array}$ & $\begin{array}{c}0.0007 \\
(\mathrm{~N}=1699)\end{array}$ & $\begin{array}{c}0.0012 \\
(\mathrm{~N}=1378)\end{array}$ & $\begin{array}{c}0.0008 \\
(\mathrm{~N}=961)\end{array}$ & 0.0001 \\
\hline & 3 & $\begin{array}{c}0.0008 \\
(\mathrm{~N}=1319)\end{array}$ & $\begin{array}{c}0.0009 \\
(\mathrm{~N}=1557)\end{array}$ & $\begin{array}{c}0.0008 \\
(\mathrm{~N}=1754)\end{array}$ & $\begin{array}{c}0.0005 \\
(\mathrm{~N}=1713)\end{array}$ & $\begin{array}{c}0.0006 \\
(\mathrm{~N}=1339)\end{array}$ & -0.0001 \\
\hline & 4 & $\begin{array}{c}0.0011 \\
(\mathrm{~N}=1006)\end{array}$ & $\begin{array}{c}0.0011 \\
(\mathrm{~N}=1351)\end{array}$ & $\begin{array}{c}0.0011 \\
(\mathrm{~N}=1530)\end{array}$ & $\begin{array}{c}0.0010 \\
(\mathrm{~N}=1811)\end{array}$ & $\begin{array}{c}0.0009 \\
(\mathrm{~N}=1979)\end{array}$ & -0.0002 \\
\hline & 5 & $\begin{array}{l}\mathbf{0 . 0 0 4 7} \\
(\mathrm{N}=935)\end{array}$ & $\begin{array}{c}0.0029 \\
(\mathrm{~N}=1142)\end{array}$ & $\begin{array}{c}0.0034 \\
(\mathrm{~N}=1344)\end{array}$ & $\begin{array}{c}0.0025 \\
(\mathrm{~N}=1730)\end{array}$ & $\begin{array}{c}0.0026 \\
(\mathrm{~N}=2507)\end{array}$ & $-0.0020^{* *}$ \\
\hline & $5-1$ & 0.0007 & 0.0004 & 0.0001 & $-0.0010^{*}$ & $-0.0020 * *$ & \\
\hline
\end{tabular}

* Significant at $p<0.05$.

** Significant at $p<0.01$.

See Table 2 for variable definitions.

Note: Unlike the final samples used for the sample descriptions and the final regression analysis, the samples used in this Table 4 include forecasts updated immediately after the earnings announcement, i.e., forecasts window is $(0,45)$ where 0 is the earnings announcement date. 
Table 5. General Pattern of Analyst Forecast Updating Behavior ${ }^{\ddagger}$

Panel A. Forecast updating promptness

\begin{tabular}{cccc}
\hline Interval & Frequency & Percent & Cumulative Percent \\
\hline 0 & 21,590 & 5.43 & 5.43 \\
1 & 112,250 & 28.24 & 33.68 \\
2 & 45,945 & 11.56 & 45.24 \\
3 & 20,832 & 5.24 & 50.48 \\
4 & 13,777 & 3.47 & 53.94 \\
5 & 10,015 & 2.52 & 56.46 \\
$6-45$ & 173,023 & 43.54 & 100.00 \\
\hline Total & 397,432 & 100.00 & - \\
\hline
\end{tabular}

Panel B. Number of forecast updates

\begin{tabular}{cccc}
\hline Number of Updates & Frequency & Percent & Cumulative Percent \\
\hline 1 & 259,760 & 65.36 & 65.36 \\
2 & 104,136 & 26.20 & 91.56 \\
3 & 19,227 & 4.84 & 96.40 \\
4 & 10,871 & 2.74 & 99.13 \\
$5<=$ & 3,438 & 0.87 & 100.00 \\
\hline Total & 397,432 & 100.00 & - \\
\hline
\end{tabular}

‡All individual analysts' annual earnings forecast updates made between 0 and 45 days after the quarterly earnings announcement are included in the sample. To be included in the sample, analysts must make one-year-ahead annual earnings forecast(s) (two-year-ahead annual earnings forecast(s) only for the fourth quarter) within forty-five days before the quarterly earnings announcement date.

Interval shows how soon analysts update their forecasts after the quarterly earnings announcement: 0 means that analysts update annual earnings forecasts on the same day as the quarterly earnings announcement date.

Number of Updates means how many times analysts update annual earnings forecasts within forty-five days after the quarterly earnings announcement. 
Table 6. Forecast Window $(0,5)$ versus Forecast Window $(6,45)$

Panel $A$. Difference of DISP (Analyst forecast dispersion) and $\Delta V$ (Change of information uncertainty) between early and late updated forecasts groups

\begin{tabular}{|c|c|c|c|c|c|c|}
\hline$\underset{\text { Decile }}{S U E[A F E}$ & $\begin{array}{l}D I S P \_0 \_5 \\
(\mathrm{~N}=27,015)\end{array}$ & $\begin{array}{c}\text { DISP_6_45 } \\
(\mathrm{N}=23,740)\end{array}$ & $\begin{array}{l}\text { Difference } \\
\text { (DISP_6_45 } \\
- \text { DISP_0_5) }\end{array}$ & $\begin{array}{c}\Delta V_{-} 0_{-} 5 \\
(\mathrm{~N}=27,015)\end{array}$ & $\begin{array}{c}\Delta V_{-}^{6} 6-45 \\
(\mathrm{~N}=23,740)\end{array}$ & $\begin{array}{c}\text { Difference } \\
\left(\Delta V_{-}^{6}{ }_{-45}\right. \\
\left.\Delta V_{-}{ }_{-} 5\right)\end{array}$ \\
\hline 1(Lowest) & 0.0044 & 0.0157 & $\begin{array}{c}0.0113^{* *} \\
(3.27)\end{array}$ & -0.0375 & -0.0427 & $\begin{array}{r}-0.0059 \\
(-1.38)\end{array}$ \\
\hline 2 & 0.0022 & 0.0019 & $\begin{array}{r}-0.0003 \\
(-0.83)\end{array}$ & -0.0168 & -0.0137 & $\begin{array}{c}0.0031 \\
(0.76)\end{array}$ \\
\hline 3 & 0.0008 & 0.0011 & $\begin{array}{c}0.0003 \\
(1.37)\end{array}$ & -0.0081 & -0.0083 & $\begin{array}{r}-0.0002 \\
(-0.18)\end{array}$ \\
\hline 4 & 0.0004 & 0.0017 & $\begin{array}{l}0.0013 \\
(1.66)\end{array}$ & -0.0038 & -0.0053 & $\begin{array}{r}-0.0015 \\
(-1.76)\end{array}$ \\
\hline 5 & 0.0007 & 0.0021 & $\begin{array}{c}0.0014 \\
(1.07)\end{array}$ & -0.0036 & -0.0041 & $\begin{array}{r}-0.0005 \\
(-0.57)\end{array}$ \\
\hline 6 & 0.0005 & 0.0008 & $\begin{array}{r}0.0003 * \\
(2.01)\end{array}$ & -0.0019 & -0.0042 & $\begin{array}{c}-0.0024 * * \\
(-4.19)\end{array}$ \\
\hline 7 & 0.0009 & 0.0016 & $\begin{array}{r}0.0007 \\
(1.57)\end{array}$ & -0.0016 & -0.0047 & $\begin{array}{c}-0.0031^{* *} \\
(-3.94)\end{array}$ \\
\hline 8 & 0.0010 & 0.0018 & $\begin{array}{c}0.0008 * * \\
(2.71)\end{array}$ & -0.0017 & -0.0059 & $\begin{array}{c}-0.0043 * * \\
(-5.32)\end{array}$ \\
\hline 9 & 0.0012 & 0.0023 & $\begin{array}{c}0.0011^{* *} \\
(3.99)\end{array}$ & -0.0036 & -0.0086 & $\begin{array}{c}-0.0050^{* *} \\
(-4.91)\end{array}$ \\
\hline 10(Highest) & 0.0036 & 0.0145 & $\begin{array}{c}0.0109^{* *} \\
(3.39) \\
\end{array}$ & -0.0147 & -0.0175 & $\begin{array}{r}-0.0030 \\
(-1.03) \\
\end{array}$ \\
\hline Mean & 0.0015 & 0.0043 & $\begin{array}{c}0.0028^{* *} \\
(4.75)\end{array}$ & -0.0090 & -0.0115 & $\begin{array}{c}-0.0024 * * \\
(-2.84)\end{array}$ \\
\hline
\end{tabular}


Table 6. Continued.

Panel $B$. Difference of $V$ (Information uncertainty) and $S E$ (Squared mean forecast error) between early and late updated forecasts groups

\begin{tabular}{|c|c|c|c|c|c|c|}
\hline$\underset{\text { Decile }}{S U E \_A F E}$ & $\begin{array}{c}V-0 \_5 \\
(\mathrm{~N}=27,015)\end{array}$ & $\begin{array}{c}V \_6 \_45 \\
(N=23,740)\end{array}$ & $\begin{array}{c}\text { Difference } \\
\left(V_{-}{ }_{-} 45-\right. \\
\left.V_{-} 0_{-} 5\right)\end{array}$ & $\underset{(\mathrm{N}=27,015)}{S E \_5}$ & $\begin{array}{c}S E \_6 \quad 45 \\
(\mathrm{~N}=23,740)\end{array}$ & $\begin{array}{c}\text { Difference } \\
\left(S E_{-} 6 \_45-\right. \\
\left.S E \_0 \_5\right)\end{array}$ \\
\hline 1(Lowest) & 0.0758 & 0.1761 & $\begin{array}{c}0.0974 * * \\
(4.11)\end{array}$ & 0.1887 & 0.1648 & $\begin{array}{c}-0.0269 \\
(-0.71)\end{array}$ \\
\hline 2 & 0.0375 & 0.0402 & $\begin{array}{c}0.0004 \\
(0.06)\end{array}$ & 0.0896 & 0.0388 & $\begin{array}{c}-0.0530 \\
(-1.22)\end{array}$ \\
\hline 3 & 0.0185 & 0.0147 & $\begin{array}{r}-0.0035 \\
(-0.85)\end{array}$ & 0.0342 & 0.0139 & $\begin{array}{l}-0.0201 \\
(-1.30)\end{array}$ \\
\hline 4 & 0.0141 & 0.0232 & $\begin{array}{r}0.0091 \\
(1.47)\end{array}$ & 0.0192 & 0.0219 & $\begin{array}{l}0.0027 \\
(0.61)\end{array}$ \\
\hline 5 & 0.0178 & 0.0170 & $\begin{array}{r}-0.0006 \\
(-0.11)\end{array}$ & 0.0189 & 0.0156 & $\begin{array}{c}-0.0031 \\
(-0.69)\end{array}$ \\
\hline 6 & 0.0099 & 0.0125 & $\begin{array}{r}0.0027 \\
(1.06)\end{array}$ & 0.0101 & 0.0119 & $\begin{array}{l}0.0018 \\
(0.72)\end{array}$ \\
\hline 7 & 0.0169 & 0.0175 & $\begin{array}{r}0.0006 \\
(0.15)\end{array}$ & 0.0229 & 0.0164 & $\begin{array}{l}-0.0065 \\
(-1.24)\end{array}$ \\
\hline 8 & 0.0148 & 0.0224 & $\begin{array}{r}0.0079 \\
(1.24)\end{array}$ & 0.0141 & 0.0211 & $\begin{array}{l}0.0073 \\
(1.13)\end{array}$ \\
\hline 9 & 0.0273 & 0.0272 & $\begin{array}{r}0.0000 \\
(0.00)\end{array}$ & 0.0286 & 0.0256 & $\begin{array}{r}-0.0030 \\
(-0.84)\end{array}$ \\
\hline 10(Highest) & 0.0503 & 0.2696 & $\begin{array}{c}0.2233^{*} \\
(2.26) \\
\end{array}$ & 0.1585 & 0.2589 & $\begin{array}{l}0.1043 \\
(1.75) \\
\end{array}$ \\
\hline Mean & 0.0274 & 0.0613 & $\begin{array}{c}0.0340^{* *} \\
(3.39)\end{array}$ & 0.0563 & 0.0582 & $\begin{array}{c}0.0019 \\
(0.24) \\
\end{array}$ \\
\hline
\end{tabular}


Table 6. Continued.

Panel $C . \Delta V$ (Change of information uncertainty) by earnings surprise quintiles: forecast window $(0,5)$

\begin{tabular}{|c|c|c|c|c|c|c|c|}
\hline \multicolumn{8}{|c|}{ SUE_RET Quintile } \\
\hline & & 1 & 2 & 3 & 4 & 5 & $5-1$ \\
\hline \multirow[t]{6}{*}{$\begin{array}{l}S U E \\
A F E \\
\text { Quintile }\end{array}$} & 1 & $\begin{array}{l}-0.0314 \\
(\mathrm{~N}=1842)\end{array}$ & $\begin{array}{l}-0.0196 \\
(\mathrm{~N}=1248)\end{array}$ & $\begin{array}{c}-0.0286 \\
(\mathrm{~N}=948)\end{array}$ & $\begin{array}{c}-0.0219 \\
(\mathrm{~N}=714)\end{array}$ & $\begin{array}{c}-0.0200 \\
(\mathrm{~N}=559)\end{array}$ & $0.0112^{*}$ \\
\hline & 2 & $\begin{array}{l}-0.0074 \\
(\mathrm{~N}=1250)\end{array}$ & $\begin{array}{l}-0.0044 \\
(\mathrm{~N}=1318)\end{array}$ & $\begin{array}{l}-0.0054 \\
(\mathrm{~N}=1196)\end{array}$ & $\begin{array}{c}-0.0054 \\
(\mathrm{~N}=958)\end{array}$ & $\begin{array}{c}-0.0046 \\
(\mathrm{~N}=667)\end{array}$ & 0.0031 \\
\hline & 3 & $\begin{array}{l}-0.0043 \\
(\mathrm{~N}=881)\end{array}$ & $\begin{array}{l}-0.0023 \\
(\mathrm{~N}=1067)\end{array}$ & $\begin{array}{l}-0.0023 \\
(\mathrm{~N}=1221)\end{array}$ & $\begin{array}{l}-0.0022 \\
(\mathrm{~N}=1218)\end{array}$ & $\begin{array}{c}-0.0009 \\
(\mathrm{~N}=973)\end{array}$ & $0.0026 * *$ \\
\hline & 4 & $\begin{array}{l}-0.0033 \\
(\mathrm{~N}=714)\end{array}$ & $\begin{array}{l}-0.0016 \\
(\mathrm{~N}=918)\end{array}$ & $\begin{array}{l}-0.0018 \\
(\mathrm{~N}=1050)\end{array}$ & $\begin{array}{l}-0.0015 \\
(\mathrm{~N}=1265)\end{array}$ & $\begin{array}{l}0.0002 \\
(\mathrm{~N}=1416)\end{array}$ & $0.0032 * *$ \\
\hline & 5 & $\begin{array}{l}-0.0176 \\
(\mathrm{~N}=637)\end{array}$ & $\begin{array}{l}-0.0108 \\
(\mathrm{~N}=819)\end{array}$ & $\begin{array}{c}-0.0072 \\
(\mathrm{~N}=949)\end{array}$ & $\begin{array}{l}-0.0054 \\
(\mathrm{~N}=1215)\end{array}$ & $\begin{array}{l}-0.0074 \\
(\mathrm{~N}=1725)\end{array}$ & 0.0094 \\
\hline & $5-1$ & 0.0083 & $0.0094 * *$ & $0.0187 * *$ & $0.0160 * *$ & $0.0123 * *$ & \\
\hline
\end{tabular}

Panel D. $\Delta V$ (Change of information uncertainty) by earnings surprise quintiles: forecast window $(6,45)$

\begin{tabular}{|c|c|c|c|c|c|c|c|}
\hline \multicolumn{8}{|c|}{ SUE_RET Quintile } \\
\hline & & 1 & 2 & 3 & 4 & 5 & $5-1$ \\
\hline \multirow[t]{6}{*}{$\begin{array}{l}S U E_{-} \\
A F E \\
\text { Quintile }\end{array}$} & 1 & $\begin{array}{l}-0.0369 \\
(\mathrm{~N}=1515)\end{array}$ & $\begin{array}{c}-0.0204 \\
(\mathrm{~N}=1082)\end{array}$ & $\begin{array}{c}-0.0252 \\
(\mathrm{~N}=839)\end{array}$ & $\begin{array}{c}-0.0234 \\
(\mathrm{~N}=678)\end{array}$ & $\begin{array}{c}-0.0356 \\
(\mathrm{~N}=560)\end{array}$ & 0.0013 \\
\hline & 2 & $\begin{array}{l}-0.0076 \\
(\mathrm{~N}=1143)\end{array}$ & $\begin{array}{c}-0.0072 \\
(\mathrm{~N}=1121)\end{array}$ & $\begin{array}{l}-0.0069 \\
(\mathrm{~N}=1008)\end{array}$ & $\begin{array}{c}-0.0064 \\
(\mathrm{~N}=815)\end{array}$ & $\begin{array}{c}-0.0051 \\
(\mathrm{~N}=642)\end{array}$ & 0.0023 \\
\hline & 3 & $\begin{array}{l}-0.0058 \\
(\mathrm{~N}=837)\end{array}$ & $\begin{array}{l}-0.0044 \\
(\mathrm{~N}=969)\end{array}$ & $\begin{array}{l}-0.0045 \\
(\mathrm{~N}=1074)\end{array}$ & $\begin{array}{l}-0.0021 \\
(\mathrm{~N}=1036)\end{array}$ & $\begin{array}{c}-0.0043 \\
(\mathrm{~N}=803)\end{array}$ & 0.0015 \\
\hline & 4 & $\begin{array}{l}-0.0084 \\
(\mathrm{~N}=616)\end{array}$ & $\begin{array}{l}-0.0061 \\
(\mathrm{~N}=850)\end{array}$ & $\begin{array}{c}-0.0061 \\
(\mathrm{~N}=941)\end{array}$ & $\begin{array}{l}-0.0051 \\
(\mathrm{~N}=1122)\end{array}$ & $\begin{array}{l}-0.0034 \\
(\mathrm{~N}=1188)\end{array}$ & $0.0049 * *$ \\
\hline & 5 & $\begin{array}{l}-0.0131 \\
(\mathrm{~N}=565)\end{array}$ & $\begin{array}{l}-0.0184 \\
(\mathrm{~N}=700)\end{array}$ & $\begin{array}{c}-0.0116 \\
(\mathrm{~N}=850)\end{array}$ & $\begin{array}{l}-0.0118 \\
(\mathrm{~N}=1071)\end{array}$ & $\begin{array}{l}-0.0126 \\
(\mathrm{~N}=1497)\end{array}$ & 0.0002 \\
\hline & $5-1$ & $0.0225 * *$ & 0.0023 & $0.0126 * *$ & $0.0146 * *$ & $0.0230 * *$ & \\
\hline
\end{tabular}

$t$-statistics are reported in parenthesis.

* Significant at $p<0.05$.

** Significant at $p<0.01$. 
DISP_0_5 [DISP_6_45]: Analysts' forecast dispersion calculated using updated annual earnings forecasts made over the trading day window $(0,5)[(6,45)]$, where 0 is the earnings announcement date and 5 is the fifth day after earnings announcement date. If the same analyst makes more than one forecast within this period, the latest forecast is used.

$\Delta V \_0 \_5\left[\Delta V \_6 \_45\right]$ : The subtraction of information uncertainty measured using forecasts made before the earnings announcement $(-45,-1)$, from information uncertainty measured using forecasts updated over the trading day window $(0,5)[(6,45)]$. To be included in the sample, the same analyst makes forecast(s) in both periods. If analysts make more than one forecast within each period, the latest forecast is used.

V_0_5 [V_6_45]: Information uncertainty measured using forecasts made over the trading day window $(0,5)[(6,45)]$. To be included in the sample, the same analyst makes forecast(s) before the earnings announcements $(-45,-1)$. If analysts make more than one forecast within each period, the latest forecast is used. See Table 2 for the calculation of $V$.

$S E \_0 \_5$ [SE_6_45]: Squared error of the mean forecast measured using forecasts updated over the trading day window $(0,5)[(6,45)]$. To be included in the sample, the same analyst makes forecast(s) before the earnings announcements $(-45,-1)$. If analysts make more than one forecast within each period, the latest forecast is used. See Table 2 for the calculation of $S E$.

Other variable definitions are in Table 2. 
Table 7. Regression Tests of the Influence of Information Uncertainty on PEAD Panel A. Forecast window $(0,5)$

\begin{tabular}{lccr} 
CAR_2_60 ${ }_{j q}=\beta_{0}+\beta_{1} S U E_{-} A F E_{j q}+\beta_{2} \Delta V_{j q} \times S U E_{-} A F E_{j q}+\varepsilon_{j q}$ & $(\mathrm{~N}=27,015)$ \\
\hline Coefficient & Expected Sign & $\begin{array}{c}\text { Parameter Estimate } \\
(\boldsymbol{t} \text {-stat) }\end{array}$ & Adjusted $\boldsymbol{R}^{2}$ \\
\hline$\beta_{0}$ Intercept & $-0.0111^{* *}$ & \\
& & $(-4.29)$ & \\
$\beta_{1} S U E_{-} A F E_{j q}$ & + & $0.0411^{* *}$ & \\
$\beta_{2}$ Chg Uncertainty & - & $(7.64)$ & 0.0023 \\
& - & $-0.0398^{* *}$ & \\
\hline
\end{tabular}

Panel B. Forecast window $(0,5)$

$$
\begin{aligned}
C A R_{-} 2_{-} 60_{j q} & =\beta_{0}+\beta_{1} S U E_{-} A F E_{j q}+\beta_{2} \Delta V_{j q} \times S U E_{-} A F E_{j q}+\beta_{3} S I Z E \times S U E_{-} A F E_{j q} \\
& +\beta_{4} V O L_{j q} \times S U E_{-} A F E_{j q}+\beta_{5} C O M P_{j q} \times S U E_{-} A F E_{j q}+\beta_{6} A N U M_{j q} \times S U E_{-} A F E_{j q} \\
& +\beta_{7} S I G N_{j q} \times S U E_{-} A F E_{j q}+\varepsilon_{j q}
\end{aligned}
$$

\begin{tabular}{|c|c|c|c|}
\hline Coefficient & Expected Sign & $\begin{array}{c}\text { Parameter Estimate } \\
\text { ( } t \text {-stat) }\end{array}$ & Adjusted $R^{2}$ \\
\hline$\beta_{0}$ Intercept & & $\begin{array}{l}-0.0073^{*} \\
(-2.40)\end{array}$ & \\
\hline$\beta_{1} S U E_{-} A F E_{j q}$ & + & $\begin{array}{l}-0.0260 \\
(-1.38)\end{array}$ & \\
\hline$\beta_{2}$ Chg Uncertainty & - & $\begin{array}{l}-0.0399 * * \\
(-5.65)\end{array}$ & \\
\hline$\beta_{3}$ Size & - & $\begin{array}{l}-0.0142 \\
(-1.70)\end{array}$ & \\
\hline$\beta_{4}$ Trading Volume & + & $\begin{array}{l}0.0034 \\
(0.45)\end{array}$ & \\
\hline$\beta_{5}$ Compound Return & + & $\begin{array}{l}0.0474^{* *} \\
(6.56)\end{array}$ & \\
\hline $\begin{array}{c}\beta_{6} \text { Number of } \\
\text { Analysts }\end{array}$ & - & $\begin{array}{l}0.0233 * * \\
(2.78)\end{array}$ & \\
\hline$\beta_{7}$ Sign of SUE & + & $\begin{array}{l}0.0311 * \\
(2.01)\end{array}$ & 0.0043 \\
\hline
\end{tabular}

$(\mathrm{N}=27,015)$ 
Table 7. Continued.

Panel C. Forecast window $(6,45)$

\begin{tabular}{lccr}
$C A R_{-} 2_{-} 60_{j q}=\beta_{0}+\beta_{1} S U E_{-} A F E_{j q}+\beta_{2} \Delta V_{j q} \times S U E_{-} A F E_{j q}+\varepsilon_{j q}$ & $(\mathrm{~N}=23,740)$ \\
\hline Coefficient & Expected Sign & $\begin{array}{c}\text { Parameter Estimate } \\
(\boldsymbol{t} \text {-stat) }\end{array}$ & Adjusted $\boldsymbol{R}^{2}$ \\
& & $-0.0331^{* *}$ & \\
\hline$\beta_{0}$ Intercept & + & $(-12.94)$ & \\
$\beta_{1} S U E_{-} A F E_{j q}$ & & $0.0305^{* *}$ & \\
$\beta_{2}$ Chg Uncertainty & + & $(5.52)$ & 0.0054 \\
& & $0.0300^{* *}$ & \\
\hline
\end{tabular}

Panel D. Forecast window $(6,45)$

$$
\begin{aligned}
C A R \_2 \_60_{j q} & =\beta_{0}+\beta_{1} S U E_{-} A F E_{j q}+\beta_{2} \Delta V_{j q} \times S U E_{-} A F E_{j q}+\beta_{3} S I Z E \times S U E_{-} A F E_{j q} \\
& +\beta_{4} V O L_{j q} \times S U E_{-} A F E_{j q}+\beta_{5} C O M P_{j q} \times S U E_{-} A F E_{j q}+\beta_{6} A N U M_{j q} \times S U E_{-} A F E_{j q} \\
& +\beta_{7} S I G N_{j q} \times S U E_{-} A F E_{j q}+\varepsilon_{j q}
\end{aligned}
$$

\begin{tabular}{|c|c|c|c|}
\hline Coefficient & Expected Sign & $\begin{array}{c}\text { Parameter Estimate } \\
(t \text {-stat })\end{array}$ & Adjusted $R^{2}$ \\
\hline$\beta_{0}$ Intercept & & $\begin{array}{l}-0.0320^{* *} \\
(-10.57)\end{array}$ & \\
\hline$\beta_{1} S U E_{-} A F E_{j q}$ & + & $\begin{array}{l}0.0012 \\
(0.08)\end{array}$ & \\
\hline$\beta_{2}$ Chg Uncertainty & + & $\begin{array}{l}0.0239 * * \\
(3.29)\end{array}$ & \\
\hline$\beta_{3}$ Size & - & $\begin{array}{l}0.0182 * \\
(2.25)\end{array}$ & \\
\hline$\beta_{4}$ Trading Volume & + & $\begin{array}{l}0.0176^{*} \\
(2.34)\end{array}$ & \\
\hline$\beta_{5}$ Compound Return & + & $\begin{array}{l}0.0398^{* *} \\
(5.49)\end{array}$ & \\
\hline $\begin{array}{c}\beta_{6} \text { Number of } \\
\text { Analysts }\end{array}$ & - & $\begin{array}{c}-0.0296 * * \\
(-3.68)\end{array}$ & \\
\hline$\beta_{7}$ Sign of SUE & + & $\begin{array}{r}0.0063 \\
(0.54)\end{array}$ & 0.0076 \\
\hline
\end{tabular}

$(\mathrm{N}=23,740)$

$t$-statistics are reported in parenthesis.

* Significant at $p<0.05$.

** Significant at $p<0.01$.

$V O L_{j q}$ : The average daily turnover of firm $j$ during the forty-five days before the quarter $q$ earnings announcement, where daily turnover is the ratio of the number of shares traded each day to the number of shares outstanding.

$C O M P_{j q}$ : The compound return of firm $j$ over the six months prior to the quarter $q$ earnings ann..

$A N U M_{j q}$ : The number of analysts who make annual earnings forecasts of firm $j$ both before and after the quarter $q$ earnings ann..

$S I G N_{j q}:$ A dummy variable equal to 1 when earnings surprise (SUE_AFE) of firm $j$ at quarter $q$ is positive; 0 when SUE_AFE is negative.

Other variable definitions are in Table 2. 
Table 8. Regression Tests of the Influence of Information Uncertainty on PEAD - When $S U E \_R E T$ is Used as an Earnings Surprise Measure

Panel A. Forecast window $(6,45)$

$C A R_{-} 2_{-} 60_{j q}=\beta_{0}+\beta_{1} S U E_{-} R E T_{j q}+\beta_{2} \Delta V_{j q} \times S U E_{-} R E T_{j q}+\varepsilon_{j q}$

$(\mathrm{N}=23,740)$

\begin{tabular}{lccc}
\hline Coefficient & Expected Sign & $\begin{array}{c}\text { Parameter Estimate } \\
(\boldsymbol{t} \text {-stat) }\end{array}$ & Adjusted $\boldsymbol{R}^{2}$ \\
\hline$\beta_{0}$ Intercept & & $-0.0288^{* *}$ & \\
$\beta_{1} S U E_{-} R E T_{j q}$ & + & $(-11.30)$ & \\
$\beta_{2}$ Chg Uncertainty & + & 0.0101 & \\
& & $(1.76)$ & 0.0056 \\
\hline
\end{tabular}

Panel B. Forecast window $(6,45)$ $\begin{aligned} C A R_{-} 2_{-} 60_{j q} & =\beta_{0}+\beta_{1} S U E \_R E T_{j q}+\beta_{2} \Delta V_{j q} \times S U E_{-} \quad R E T_{j q}+\beta_{3} S I Z E \times S U E_{-} R E T_{j q} \\ & +\beta_{4} V O L_{j q} \times S U E_{-} R E T_{j q}+\beta_{5} C O M P_{j q} \times S U E_{-} R E T_{j q}+\beta_{6} A N U M_{j q} \times S U E_{-} R E T_{j q} \\ & +\beta_{7} S I G N_{j q} \times S U E_{-} R E T_{j q}+\varepsilon_{j q}\end{aligned}$

$t$-statistics are reported in parenthesis.

* Significant at $p<0.05$.

** Significant at $p<0.01$.

See Table 2 and Table 7 for variable definitions. 
Table 9. Regression Tests of the Influence of Information Uncertainty on PEAD - When Level of Uncertainty is Used Instead of Change of Uncertainty

Panel A. Forecast window $(6,45)$

\begin{tabular}{lccr}
$C A R \_2 \_60_{j q}=\beta_{0}+\beta_{1} S U E_{-} R E T_{j q}+\beta_{2} V_{j q} \times S U E_{-} R E T_{j q}+\varepsilon_{j q}$ & $(\mathrm{~N}=49,594)$ \\
\hline Coefficient & Expected Sign & $\begin{array}{c}\text { Parameter Estimate } \\
(\boldsymbol{t} \text {-stat) }\end{array}$ & Adjusted $\boldsymbol{R}^{2}$ \\
\hline$\beta_{0}$ Intercept & $-0.0188^{* *}$ & \\
& & $(-10.45)$ & \\
$\beta_{1} S U E \_R E T_{j q}$ & + & $0.0314^{* *}$ & \\
$\beta_{2}$ Uncertainty & & $(7.90)$ & 0.0030 \\
& + & 0.0093 & \\
\hline
\end{tabular}

Panel B. Forecast window (6, 45)

$$
\begin{aligned}
C A R \_2 \_60_{j q} & =\beta_{0}+\beta_{1} S U E_{-} R E T_{j q}+\beta_{2} V_{j q} \times S U E_{-} R E T_{j q}+\beta_{3} S I Z E \times S U E_{-} R E T_{j q} \\
& +\beta_{4} V O L_{j q} \times S U E_{-} R E T_{j q}+\beta_{5} C O M P_{j q} \times S U E_{-} R E T_{j q}+\beta_{6} A N U M_{j q} \times S U E_{-} R E T_{j q} \\
& +\beta_{7} S I G N_{j q} \times S U E_{-} R E T_{j q}+\varepsilon_{j q}
\end{aligned}
$$

\begin{tabular}{|c|c|c|c|}
\hline Coefficient & Expected Sign & $\begin{array}{c}\text { Parameter Estimate } \\
(t \text {-stat })\end{array}$ & Adjusted $R^{2}$ \\
\hline$\beta_{0}$ Intercept & & $\begin{array}{c}-0.0173^{* *} \\
(-9.51)\end{array}$ & \\
\hline$\beta_{1} S U E_{-} R E T_{j q}$ & + & $\begin{array}{c}0.0014 \\
(0.20)\end{array}$ & \\
\hline$\beta_{2}$ Uncertainty & + & $\begin{array}{c}0.0149^{* *} \\
(2.81)\end{array}$ & \\
\hline$\beta_{3}$ Size & - & $\begin{array}{r}-0.0055 \\
(-0.90)\end{array}$ & \\
\hline$\beta_{4}$ Trading Volume & + & $\begin{array}{r}0.0073 \\
(1.36)\end{array}$ & \\
\hline$\beta_{5}$ Compound Return & + & $\begin{array}{c}0.0423 * * \\
(8.34)\end{array}$ & \\
\hline $\begin{array}{c}\beta_{6} \text { Number of } \\
\text { Analysts }\end{array}$ & - & $\begin{array}{c}-0.0236 * * \\
(-3.91)\end{array}$ & \\
\hline$\beta_{7}$ Sign of SUE & + & $\begin{array}{c}0.0194 * * \\
(5.18)\end{array}$ & 0.0058 \\
\hline
\end{tabular}

$(\mathrm{N}=49,594)$

$t$-statistics are reported in parenthesis.

* Significant at $p<0.05$.

** Significant at $p<0.01$.

See Table 2 and Table 7 for variable definitions. 
Table 10. Regression Tests of the Influence of Information Uncertainty on PEAD - Sub-sample Tests

$$
\begin{aligned}
C A R_{-} 2_{-} 60_{j q} & =\beta_{0}+\beta_{1} S U E_{-} R E T_{j q}+\beta_{2} \Delta V_{j q} \times S U E_{-} R E T_{j q}+\beta_{3} S I Z E \times S U E_{-} R E T_{j q} \\
& +\beta_{4} V O L_{j q} \times S U E_{2} R E T_{j q}+\beta_{5} C O M P_{j q} \times S U E_{-} R E T_{j q}+\beta_{6} A N U M_{j q} \times S U E_{-} R E T_{j q} \\
& +\beta_{7} S I G N_{j q} \times S U E_{-} R E T_{j q}+\varepsilon_{j q}
\end{aligned}
$$

Panel A. Sub-sample test by quarters

$(\mathrm{N}=23,740)$

Parameter Estimate

( $t$-statistic)

\begin{tabular}{lllll}
\hline Coefficient & $\begin{array}{c}\text { 1st Qtr } \\
(\mathbf{N}=7,528)\end{array}$ & $\begin{array}{c}\text { 2nd Qtr } \\
(\mathbf{N = 6 , 7 9 5 )}\end{array}$ & $\begin{array}{c}\text { 3rd Qtr } \\
\mathbf{( N = 7 , 3 1 0 )}\end{array}$ & $\begin{array}{c}\text { 4th Qtr } \\
\mathbf{( N = 2 , 1 0 7 )}\end{array}$ \\
\hline$\beta_{0}$ Intercept & $-0.0301^{* *}$ & $-0.0393^{* *}$ & $-0.0145^{* *}$ & $-0.0265^{* *}$ \\
$\beta_{1} S U E_{-} R E T_{j q}$ & $(-6.87)$ & $(-8.28)$ & $(-2.98)$ & $(-3.08)$ \\
& -0.0223 & $-0.0487^{* *}$ & -0.0172 & $0.0700^{*}$ \\
$\boldsymbol{\beta}_{2}$ Chg Uncertainty & $(-1.42)$ & $(-2.79)$ & $(-0.90)$ & $(2.15)$ \\
& $\mathbf{0 . 0 4 0 3 * *}$ & $\mathbf{0 . 1 0 3 6 * *}$ & $\mathbf{- 0 . 0 0 6 2}$ & $\mathbf{0 . 0 4 9 8 *}$ \\
$\beta_{3}$ Size & $\mathbf{( 3 . 3 0 )}$ & $\mathbf{( 7 . 3 6 )}$ & $\mathbf{( - 0 . 4 0 )}$ & $\mathbf{( 2 . 2 5 )}$ \\
$\beta_{4}$ Trading Volume & -0.0131 & -0.0113 & $0.0474^{* *}$ & -0.0489 \\
& $(-0.98)$ & $(-0.76)$ & $(3.04)$ & $(-1.76)$ \\
$\beta_{5}$ Compound Return & -0.0101 & -0.0113 & $0.0774^{* *}$ & -0.0327 \\
& $(-0.80)$ & $(-0.81)$ & $(5.27)$ & $(-1.33)$ \\
$\beta_{6}$ Number of & $0.0852^{* *}$ & $0.1075^{* *}$ & -0.0146 & 0.0132 \\
Analysts & $(7.08)$ & $(8.03)$ & $(-1.04)$ & $(0.54)$ \\
$\beta_{7}$ Sign of SUE & -0.0191 & -0.0196 & $-0.0543^{* *}$ & 0.0097 \\
& $(-1.42)$ & $(-1.32)$ & $(-3.50)$ & $(0.37)$ \\
Adjusted $R^{2}$ & $0.0222^{*}$ & -0.0009 & 0.0175 & 0.0176 \\
& $(2.48)$ & $(-0.09)$ & $(1.76)$ & $(1.06)$ \\
\hline
\end{tabular}


Table 10. Continued.

Panel B. Sub-sample test by years

$(\mathrm{N}=23,740)$

Parameter Estimate

( $t$-statistic)

\begin{tabular}{|c|c|c|c|c|c|c|}
\hline Coefficient & 1989-1991 & 1992-1994 & 1995-1997 & 1998-2000 & 2001-2003 & 2004-2005 \\
\hline$\beta_{0}$ Intercept & $\begin{array}{l}-0.0275^{* *} \\
(-5.36)\end{array}$ & $\begin{array}{l}-0.0238^{* *} \\
(-4.81)\end{array}$ & $\begin{array}{l}-0.0302^{* *} \\
(-5.49)\end{array}$ & $\begin{array}{l}-0.0502 * * \\
(-6.57)\end{array}$ & $\begin{array}{l}-0.0158^{*} \\
(-2.41)\end{array}$ & $\begin{array}{l}-0.0095 \\
(-1.79)\end{array}$ \\
\hline$\beta_{1} S U E_{-} R E T_{j q}$ & $\begin{array}{l}0.0124 \\
(0.68)\end{array}$ & $\begin{array}{l}0.0173 \\
(0.93)\end{array}$ & $\begin{array}{l}-0.0438^{*} \\
(-2.12)\end{array}$ & $\begin{array}{l}-0.1267^{* *} \\
(-4.54)\end{array}$ & $\begin{array}{l}0.0470 \\
(1.86)\end{array}$ & $\begin{array}{l}0.0118 \\
(0.57)\end{array}$ \\
\hline $\begin{array}{l}\boldsymbol{\beta}_{2} \text { Chg } \\
\text { Uncertainty }\end{array}$ & $\begin{array}{l}0.0761 * * \\
(5.02)\end{array}$ & $\begin{array}{l}0.0050 \\
(0.35)\end{array}$ & $\begin{array}{l}0.0666^{* *} \\
(4.13)\end{array}$ & $\begin{array}{l}0.1043^{* *} \\
(4.58)\end{array}$ & $\begin{array}{l}0.0122 \\
(0.64)\end{array}$ & $\begin{array}{c}-0.0206 \\
(-1.33)\end{array}$ \\
\hline$\beta_{3}$ Size & $\begin{array}{c}-0.0145 \\
(-0.84)\end{array}$ & $\begin{array}{l}0.0128 \\
(0.77)\end{array}$ & $\begin{array}{c}-0.0045 \\
(-0.25)\end{array}$ & $\begin{array}{l}0.0271 \\
(1.16)\end{array}$ & $\begin{array}{c}-0.0310 \\
(-1.57)\end{array}$ & $\begin{array}{l}0.0136 \\
(0.84)\end{array}$ \\
\hline $\begin{array}{l}\beta_{4} \text { Trading } \\
\text { Volume }\end{array}$ & $\begin{array}{l}0.0168 \\
(1.06)\end{array}$ & $\begin{array}{l}0.0073 \\
(0.48)\end{array}$ & $\begin{array}{c}-0.0071 \\
(-0.44)\end{array}$ & $\begin{array}{l}0.0724 * * \\
(3.32)\end{array}$ & $\begin{array}{c}-0.0192 \\
(-1.03)\end{array}$ & $\begin{array}{c}-0.0006 \\
(-0.04)\end{array}$ \\
\hline $\begin{array}{l}\beta_{5} \text { Compound } \\
\text { Rreturn }\end{array}$ & $\begin{array}{l}-0.0208 \\
(-1.43)\end{array}$ & $\begin{array}{r}-0.0154 \\
(-1.10)\end{array}$ & $\begin{array}{l}0.0359^{*} \\
(2.31)\end{array}$ & $\begin{array}{l}0.1820^{* *} \\
(8.19)\end{array}$ & $\begin{array}{l}0.0231 \\
(1.27)\end{array}$ & $\begin{array}{l}0.0582 * * \\
(3.90)\end{array}$ \\
\hline $\begin{array}{c}\beta_{6} \text { Number of } \\
\text { Analysts }\end{array}$ & $\begin{array}{c}-0.0062 \\
(-0.35)\end{array}$ & $\begin{array}{l}0.0033 \\
(0.21)\end{array}$ & $\begin{array}{c}-0.0287 \\
(-1.63)\end{array}$ & $\begin{array}{c}-0.0594^{*} \\
(-2.49)\end{array}$ & $\begin{array}{c}-0.0365 \\
(-1.85)\end{array}$ & $\begin{array}{l}0.0097 \\
(0.60)\end{array}$ \\
\hline$\beta_{7}$ Sign of SUE & $\begin{array}{l}0.0254 * * \\
(2.61)\end{array}$ & $\begin{array}{l}0.0232^{*} \\
(2.39)\end{array}$ & $\begin{array}{l}0.0371^{* *} \\
(3.25)\end{array}$ & $\begin{array}{l}0.0052 \\
(0.32)\end{array}$ & $\begin{array}{l}0.0114 \\
(0.80)\end{array}$ & $\begin{array}{c}-0.0103 \\
(-0.88)\end{array}$ \\
\hline Adjusted $R^{2}$ & 0.0273 & 0.0093 & 0.0129 & 0.0323 & 0.0045 & 0.0106 \\
\hline
\end{tabular}

$t$-statistics are reported in parenthesis.

* Significant at $p<0.05$.

** Significant at $p<0.01$.

See Table 2 and Table 7 for variable definitions. 


\section{Table 11. Fama-MacBeth Regression Tests}

Panel A. Forecast window (6, 45)

\begin{tabular}{|c|c|c|c|}
\hline Coefficient & Expected Sign & $\begin{array}{c}\text { Parameter Estimate } \\
(t \text {-stat })\end{array}$ & Adjusted $R^{2}$ \\
\hline$\beta_{0}$ Intercept & & $\begin{array}{c}-0.0260^{* *} \\
(-4.88)\end{array}$ & \\
\hline$\beta_{1} S U E_{-} R E T_{j q}$ & + & $\begin{array}{l}0.0110 \\
(1.21)\end{array}$ & \\
\hline$\beta_{2}$ Chg Uncertainty & + & $\begin{array}{l}0.0580 * * \\
(4.50)\end{array}$ & 0.0150 \\
\hline
\end{tabular}

Panel B. Forecast window $(6,45)$

$$
\begin{aligned}
C A R_{-}{ }_{2} 60_{j q} & =\beta_{0}+\beta_{1} S U E_{-} R E T_{j q}+\beta_{2} \Delta V_{j q} \times S U E_{-} R E T_{j q}+\beta_{3} S I Z E \times S U E_{-} R E T_{j q} \\
& +\beta_{4} V O L_{j q} \times S U E_{-} R E T_{j q}+\beta_{5} C O M P_{j q} \times S U E_{-} R E T_{j q}+\beta_{6} A N U M_{j q} \times S U E_{-} R E T_{j q} \\
& +\beta_{7} S I G N_{j q} \times S U E_{-} R E T_{j q}+\varepsilon_{j q}
\end{aligned}
$$

\begin{tabular}{|c|c|c|c|}
\hline Coefficient & Expected Sign & $\begin{array}{c}\text { Parameter Estimate } \\
(t \text {-stat })\end{array}$ & Adjusted $R^{2}$ \\
\hline$\beta_{0}$ Intercept & & $\begin{array}{l}-0.0250 * * \\
(-4.47)\end{array}$ & \\
\hline$\beta_{1} S U E \_R E T_{j q}$ & + & $\begin{array}{r}-0.0090 \\
(-0.45)\end{array}$ & \\
\hline$\beta_{2}$ Chg Uncertainty & + & $\begin{array}{l}0.0410^{* *} \\
(3.29)\end{array}$ & \\
\hline$\beta_{3}$ Size & - & $\begin{array}{r}0.0050 \\
(0.38)\end{array}$ & \\
\hline$\beta_{4}$ Trading Volume & + & $\begin{array}{r}0.0150 \\
(0.65)\end{array}$ & \\
\hline$\beta_{5}$ Compound Return & + & $\begin{array}{l}0.0440^{* *} \\
(2.52)\end{array}$ & \\
\hline $\begin{array}{c}\beta_{6} \text { Number of } \\
\text { Analysts }\end{array}$ & - & $\begin{array}{l}-0.0310 \\
(-1.81)\end{array}$ & \\
\hline$\beta_{7}$ Sign of SUE & + & $\begin{array}{l}0.0130 \\
(1.72) \\
\end{array}$ & 0.0560 \\
\hline
\end{tabular}

$(\mathrm{N}=23,740)$

$t$-statistics are reported in parenthesis.

* Significant at $p<0.05$.

** Significant at $p<0.01$.

See Table 2 and Table 7 for variable definitions.

The results represent Fama-MacBeth regressions for 68 cross-sections from the first quarter of 1989 to the fourth quarter of 2005. I compute the time-series means of regression coefficients $\beta_{0}, \beta_{1}, \ldots, \beta_{7}$. 
(A) Low

Information

Uncertainty

Firm

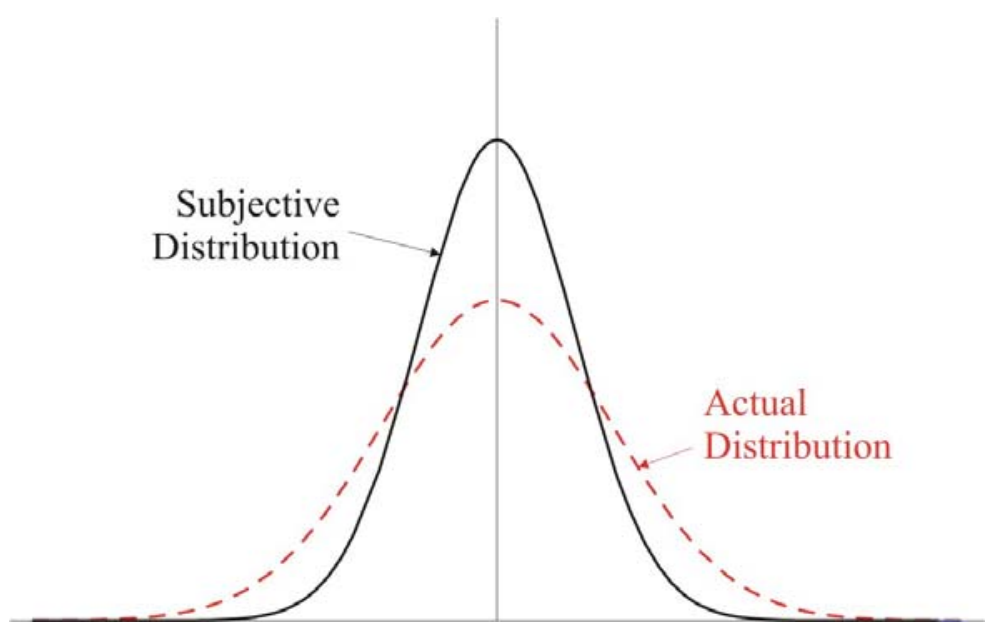

Firm Value Estimate

(B) High

Information

Uncertainty

Firm

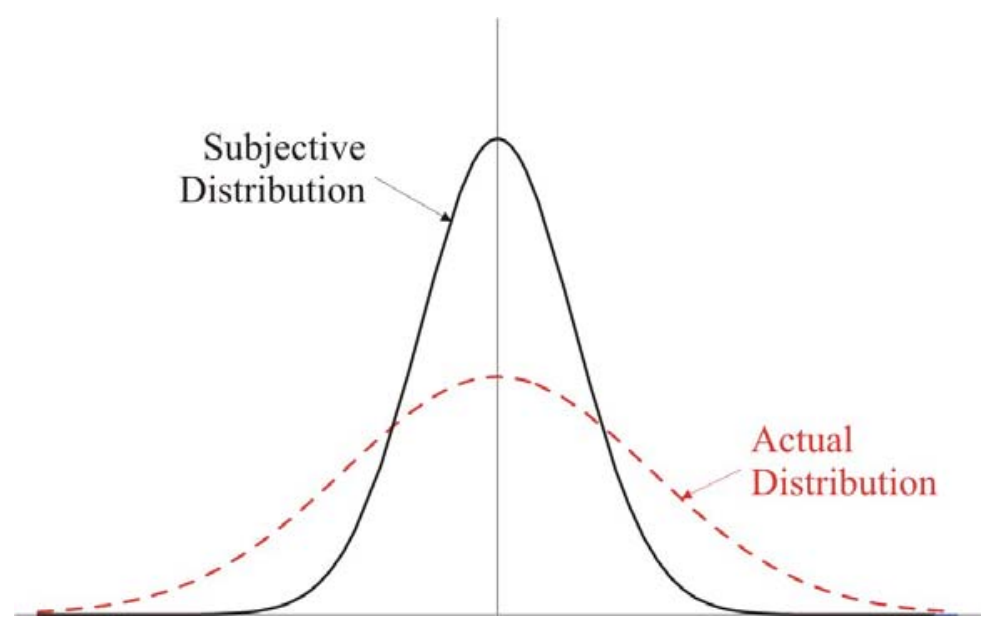

Firm Value Estimate

\section{Figure 1. Overconfidence in Firm Value Estimation.}

(A) Investors' distribution of subjective estimates is too narrow relative to the actual underlying distribution.

(B) The overconfidence bias is exacerbated by increased information uncertainty. In a high information uncertainty setting, the actual underlying distribution of firm value estimates is more diffused. To the extent that investors' subjective assessment of probabilities does not fully adjust for the increased variance in the underlying distribution, investors' behavior will exhibit patterns consistent with elevated levels of overconfidence.

Figure 1 is a reproduction from Jiang et al. (2005). 


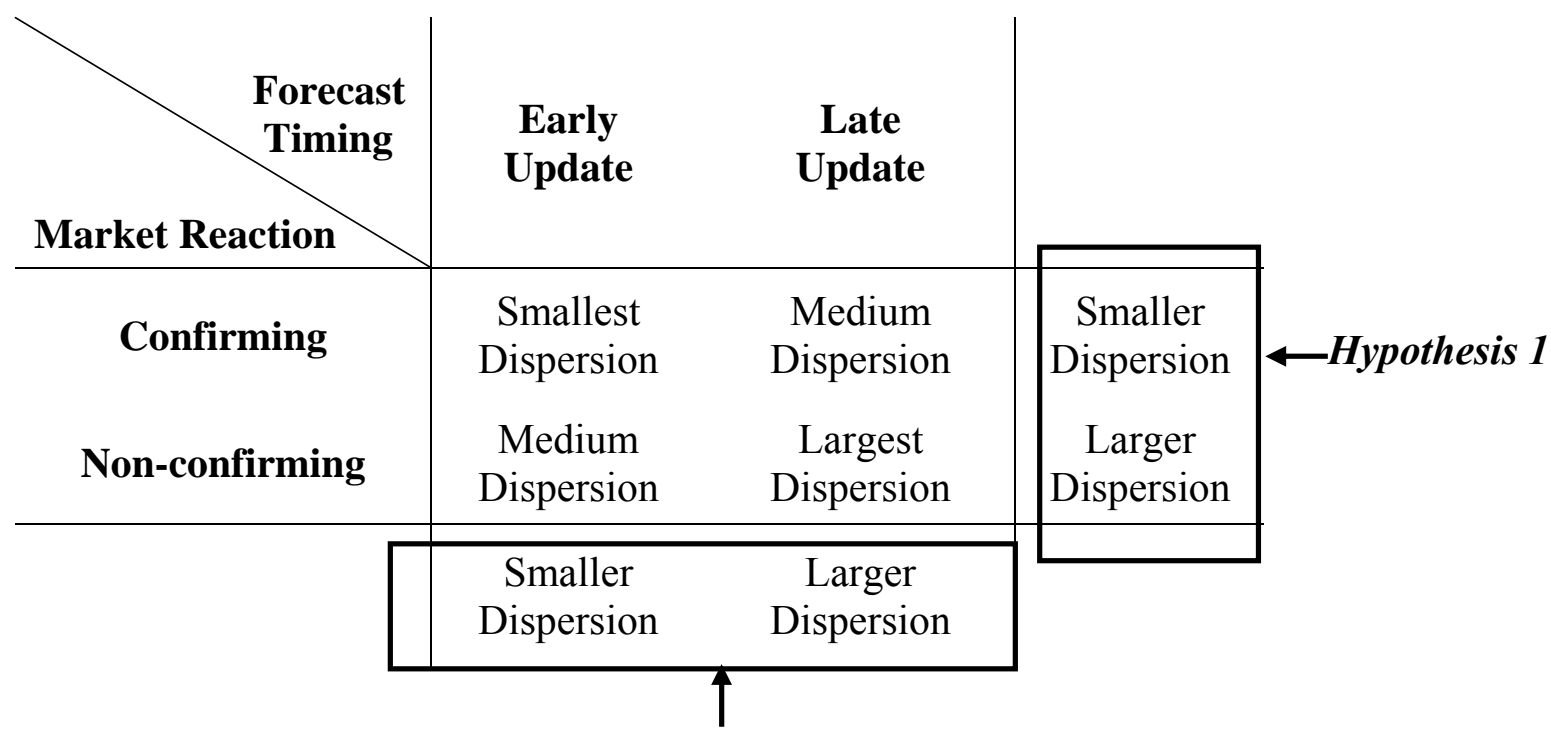

Hypothesis 2

Figure 2. The Combination of Hypothesis 1 and Hypothesis 2.

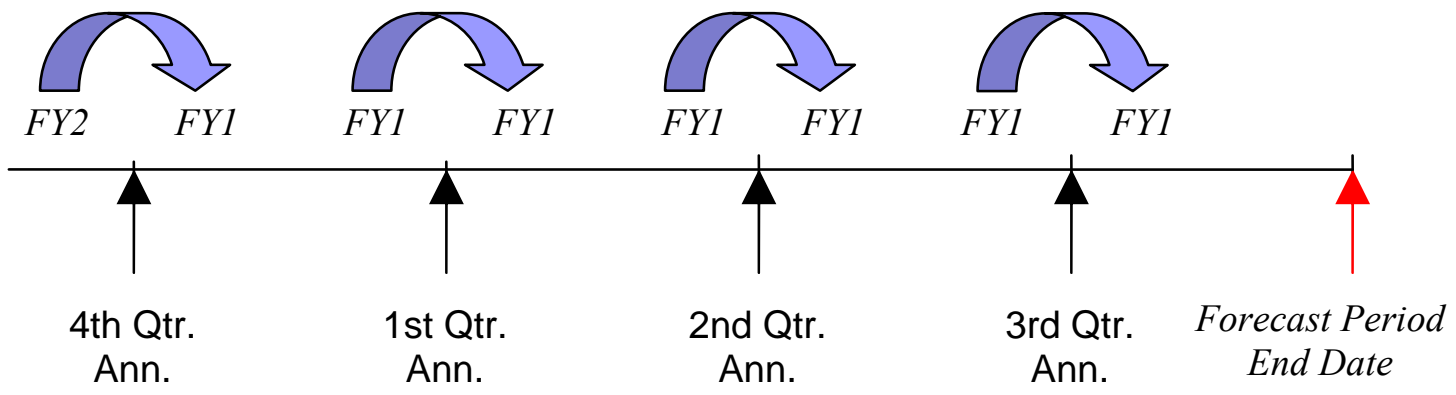

Figure 3. Analysts’ Forecasts and Forecast Horizons 


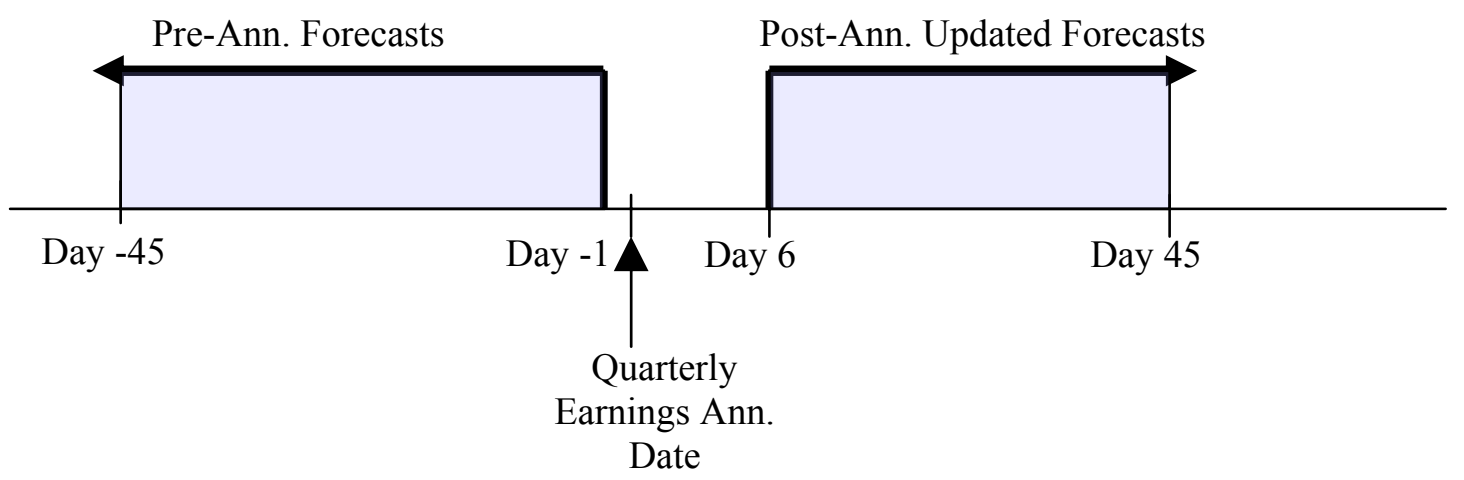

Figure 4. Forecast Collection Timing 
(A)

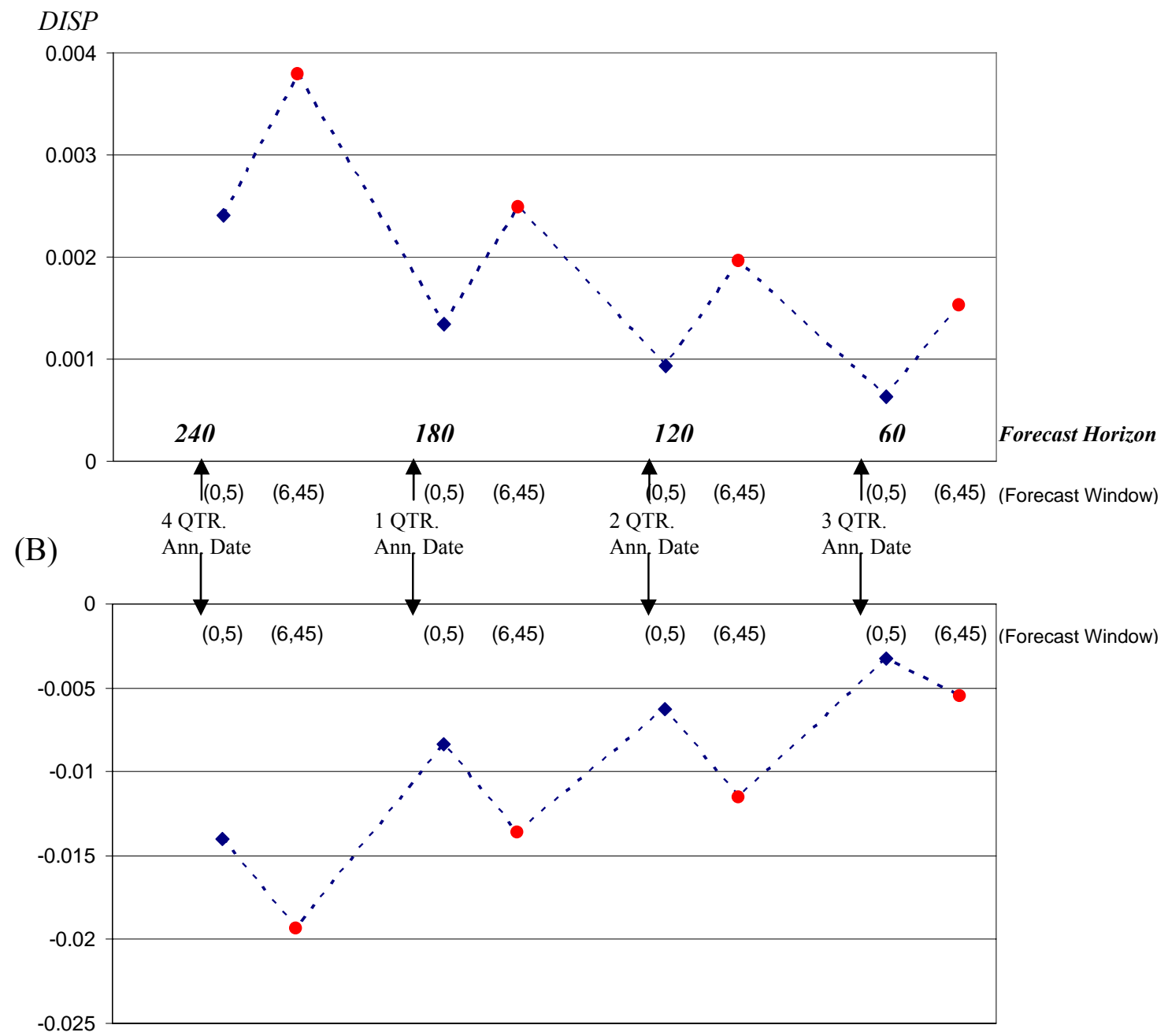

$\Delta V$ (Change of Uncertainty)

\section{Figure 5. Changing Pattern of Analyst Forecast Dispersion and Change of Uncertainty}

(A) Mean analyst forecast dispersion over one year forecast horizon: dispersion decreases as forecast horizon becomes short. However, dispersion of forecast window $(6,45)$ is larger than the dispersion of forecast window $(0,5)$ after each quarterly earnings announcement date, although the forecast horizon is shorter.

(B) Mean change of uncertainty over one year forecast horizon: absolute value of change of uncertainty decreases (i.e., less change of uncertainty) as forecast horizon becomes short. Similar to (A), there is more change of uncertainty (i.e., larger absolute value of change of uncertainty) of forecast window $(6,45)$ than in the case of forecast window $(0,5)$ after each quarterly earnings announcement date. 


\section{References}

Agrawal, A., S. Chadha, and M. A. Chen. 2006. Who is Afraid of Reg FD? The Behavior and Performance of Sell-Side Analysts Following the SEC's Fair Disclosure Rules. Journal of Business, Forthcoming.

Alti, A., R. Kaniel, and U. Yoeli. 2006. Why Do Investors Chase Return Trends? Working Paper, University of Texas at Austin.

Atiase, R. 1985. Predisclosure Information, Firm Capitalization, and Security Price Behavior around Earnings Announcement. Journal of Accounting Research, 2136.

Ayers, B. and R. N. Freeman. 2003. Evidence that Analysts Following and Institutional Ownership Accelerate the Pricing of Future Earnings. Review of Accounting Studies 8, 47-67.

Baber, W. R. and S. Kang. 2002. The Impact of Split Adjusting and Rounding on Analysts' Forecast Error Calculations. Accounting Horizons 16, 277-289.

Bailey, W., H. Li, C. X. Mao, and R. Zhong. 2003. Regulation Fair Disclosure and Earnings Information: Market, Analyst and Corporate Responses. The Journal of Finance 58, 2487-2514.

Ball, R. and P. Brown. 1968. An Empirical Evaluation of Accounting Numbers. Journal of Accounting Research 6, 159-178.

Barberis, N., A. Shleifer, and R. Vishny. 1998. A Model of Investor Sentiment. Journal of Financial Economics 49, 307-343.

Barron, O., O. Kim, D. Lim, and D. Stevens. 1998. Using Analysts' Forecasts to Measure Properties of Analysts' Information Environment. The Accounting Review 73, 421-433.

Barron, O. and P. Stuerke. 1998. Dispersion in Analysts' Earnings Forecasts as a Measure of Uncertainty. Journal of Accounting, Auditing and Finance 13, 243268.

Bartov, E., S. Radhakrishnan, and I. Krinsky. 2000. Investor Sophistication and Patterns in Stock Returns after Earnings Announcements. The Accounting Review 75, 43-63. 
Bernard, V. and J. Thomas. 1989. Post-Earnings-Announcement Drift: Delayed Price Response of Risk Premium? Journal of Accounting Research 27, 1-48.

Bernard, V. and J. Thomas. 1990. Evidence that Stock Prices Do Not Fully Reflect the Implications of Current Earnings for Future Earnings. Journal of Accounting and Economics 13, 305-341.

Bhushan, R. 1994. An Informational Efficiency Perspective on the Post-Earnings Announcement Drift. Journal of Accounting and Economics 18, 45-65.

Bloomfield, R., R. Libby, and M. Nelson. 2000. Underreactions and Overreactions: The Influence of Information Reliability and Portfolio Formation Rules. Journal of Financial Markets 3, 113-137.

Botosan, C. A. 1997. Disclosure Level and the Cost of Equity Capital. The Accounting Review 72, 323-349.

Chan, L., N. Jegadeesh, and J. Lakonishok. 1996. Momentum Strategies. The Journal of Finance 51, 1681-1713.

Chordia, T. and L. Shivakumar. 2006. Earnings and Price Momentum. Journal of Financial Economics 80, 627-656

Clement, M. B., R. Frankel, and J. Miller. 2003. Confirming Management Earnings Forecasts, Earnings Uncertainty, and Stock Returns. Journal of Accounting Research 41, 653-679.

Clement, M. B. and S.Y. Tse. 2003. Do Investors Respond to Analysts' Forecast Revisions as if Forecast Accuracy is All That Matters? The Accounting Review $78,227-249$.

Clement, M. B. and S.Y. Tse. 2005. Financial Analyst Characteristics and Herding Behavior in Forecasting. The Journal of Finance 60, 307-341.

Daniel, K., D. Hirshleifer, and A. Subrahmanyam. 1998. Investor Psychology and Security Market Under- and Overreactions. The Journal of Finance 53, 18391885 .

Daniel, K., D. Hirshleifer, and A. Subrahmanyam. 2001. Overconfidence, Arbitrage, and Equilibrium Asset Pricing. The Journal of Finance 56, 921-965. 
Dechow, P., R. Sloan, and M. Soliman. 2004. Implied Equity Duration: A New Measure of Equity Security Risk. Review of Accounting Studies 9, 197-228.

Diether, K., C. Malloy, and A. Scherbina. 2002. Differences of Opinion and the Cross-Section of Stock Returns. The Journal of Finance 57, 2113-2141.

Dische, A. 2002. Dispersion in Analyst Forecasts and the Profitability of Earnings Momentum Strategies. European Financial Management 8, 211-228.

Edwards, W., 1968. Conservatism in Human Information Processing. In: Kleinmutz, B. (Ed.), Formal Representation of Human Judgment. John Wiley and Sons, New York, 17-52.

Foster, G., C. Olsen, and T. Shevlin. 1984. Earnings Releases, Anomalies, and the Behavior of Securities Returns. The Accounting Review 59, 574-603.

Francis, J., R. LaFond, P. Olsson, and K. Schipper. 2004. Costs of Equity and Earnings Attributes. The Accounting Review 79, 967-1010.

Francis, J., R. LaFond, P. Olsson, and K. Schipper. 2005. The Market Pricing of Accruals Quality. Journal of Accounting and Economics 39, 295-327.

Frankel, R. and C. M. C. Lee. 1998. Accounting Valuation, Market Expectation, and Cross-sectional Stock Returns. Journal of Accounting and Economics 25, 283319.

Freeman, R. N. 1987. The Association between Accounting Earnings and Security Returns for Large and Small Firms. Journal of Accounting and Economics 9, 195 228.

Freeman, R. N. and S. Tse. 1989. The Multi-period Information Content of Earnings Announcement: Rational Delayed Reactions to Earnings News. Journal of Accounting Research, Suppl., 49-79.

Gebhardt, W. R., C. M. C. Lee, and B. Swaminathan. 2001. Toward an Implied Cost of Capital. Journal of Accounting Research 39, 135-176.

Griffin, D. and A. Tversky. 1992. The Weighting of Evidence and the Determinants of Confidence. Cognitive Psychology 24, 411-435.

Heflin, F, K. R. Subramanyam, and Y. Zhang. 2003. Regulation FD and the Financial Information Environment: Early Evidence. The Accounting Review 78, 1-37. 
Hong, H., J. D. Kubik, and A. Solomon. 2000. Security Analysts' Career Concerns and Herding of Earnings Forecasts. The RAND Journal of Economics 31, 121-144.

Hong, H., T. Lim, and J. C. Stein. 2000. Bad News Travels Slowly: Size, Analyst Coverage, and the Profitability of Momentum Strategies. The Journal of Finance $55,265-295$.

Hong, H. and J. C. Stein. 1999. A Unified Theory of Underreaction, Momentum Trading, and Overreaction in Asset Markets. The Journal of Finance 54, 21432184.

Imhoff, E. A. and G. J. Lobo. 1992. The Effect of Ex Ante Earnings Uncertainty on Earnings Response Coefficients. The Accounting Review 67, 427-439.

Jiang, G., C. Lee, and Y. Zhang. 2005. Information Uncertainty and Expected Returns. Review of Accounting Studies 10,185-221.

Kimbrough, M. D. 2005. The Effect of Conference Calls on Analyst and Market Underreaction to Earnings Announcements. The Accounting Review 80, 189-219.

Lang, M. and R. Lundholm. 1996. Corporate Disclosure Policy and Analyst Behavior. The Accounting Review 71, 467-491.

Lee, C. and B. Swaminathan. 2000. Price Momentum and Trading Volume. The Journal of Finance 55, 2017-2070.

Liang, L. 2003. Post-Earnings Announcement Drift and Market Participants' Information Processing Biases. Review of Accounting Studies 8, 321-345.

Liu, J. and J. Thomas. 2000. Stock Returns and Accounting Earnings. Journal of Accounting Research 38, 71-101.

Miller, J. and L. Sedor. 2006. The Influence of Observed Stock Price Changes on Analysts' Earnings Forecast Revisions: Experimental Evidence. Working paper. University of Notre Dame

Morse, D., J. Stephan, and E. K. Stice. 1991. Earnings Announcements and the Convergence (or Divergence) of Beliefs. The Accounting Review 66, 376-388.

Odean, T. 1998. Volume, Volatility, Price, and Profit when all Traders are Above Average. The Journal of Finance 53, 1887-1934. 
Trueman, B. 1994. Analyst Forecasts and Herding Behavior. The Review of Financial Studies 7, 97-124.

Schipper, K. 1991. Commentary of Analysts' Forecasts. Accounting Horizons 5, 105121. 


\section{Vita}

Joonho Lee was born in Seoul, Korea on May 28, 1969, the son of Yonghee Lee and Munja Park. He attended Seoul National University in 1988 and received the degree of Bachelor of Business Administration in 1992. He continued his study at Seoul National University and received the degree of Master of Business Administration in 1995. Following

Graduation, he was employed by Samsung Corporation in Seoul, Korea. In September 1999, he entered the University of Texas at Austin. He received the degree of Master in Professional Accounting in May 2001. In September 2001, he entered the doctoral program in Accounting at the University of Texas at Austin.

Permanent address: 6800 McNeil Drive \#521, Austin, TX 78729

This dissertation was typed by the author. 